\title{
Alkali metal complexes of the dipeptides PheAla and AlaPhe: IRMPD spectroscopy
}

by

Nick C. Polfer, ${ }^{[\mathrm{a}]}$ Jos Oomens $^{[\mathrm{b}]}$ and Robert C. Dunbar* ${ }^{[\mathrm{c}]}$

${ }^{[a]}$ Fritz-Haber-Intitute of the Max-Planck-Society, Faradayweg 4 - 6, D-14195 Berlin, Germany; Present address: Chemistry Department, University of Florida, Gainesville, FL 32611, USA

${ }^{[b]}$ FOM-Institute for Plasmaphysics Rijnhuizen, Edisonbaan 14, NL-3439 MN Nieuwegein, The Netherlands

${ }^{[c]}$ Chemistry Department, Case Western Reserve University, Cleveland, Ohio 44106, USA

Keywords: Ion spectroscopy; IR spectroscopy; mass spectrometry; peptides; alkali complexes 


\section{Abstract}

Complexes of PheAla and AlaPhe with alkali metal ions $\mathrm{Na}^{+}$and $\mathrm{K}^{+}$were generated by electrospray ionization, isolated in the Fourier-transform ion cyclotron resonance (FT-ICR) ion trapping mass spectrometer, and investigated spectroscopically by infrared multiple-photon dissociation (IRMPD) using light from the FELIX free electron laser over the mid-infrared range from 500 to $1900 \mathrm{~cm}^{-1}$. Conclusions about structural features of the complexes were drawn by comparison with predicted spectra and relative free energies calculated by DFT for a number of candidate conformers. Combining spectroscopic and energetic results, it is established that the metal ion is always chelated by the amide carbonyl oxygen, and that the C-terminal hydroxyl does not complex the metal ion and is in the endo conformation. It is also likely that the aromatic ring of Phe always chelates the metal ion in a cation- $\pi$ binding configuration. Along with the amide $\mathrm{CO}$ and ring chelation sites, a third Lewis-basic group almost certainly chelates the metal ion, giving a threefold chelation geometry. This third site may be either the Cterminal carbonyl oxygen, or the $\mathrm{N}$-terminal amino nitrogen. From the spectroscopic and computational evidence, a slight preference was given to the carbonyl group, in an $\mathrm{RO}_{\mathrm{a}} \mathrm{O}_{t}$ chelation pattern, but the amino group is almost equally likely (particularly for $\mathrm{K}^{+}$PheAla) in an $\mathrm{RO}_{\mathrm{a}} \mathrm{N}_{\mathrm{t}}$ chelation pattern, and either of these conformations, or a mixture of them, would be consistent with the present evidence. (R represents the $\pi$ ring site, $\mathrm{O}_{\mathrm{a}}$ the amide oxygen, $\mathrm{O}_{\mathrm{t}}$ the terminal carbonyl oxygen, and $\mathrm{N}_{\mathrm{t}}$ the terminal nitrogen.) The spectroscopic findings are in better agreement with the MPW1PW91 DFT functional calculations of the thermochemistry compared with the B3LYP functional, which seems to underestimate the importance of the cation- $\pi$ interaction. 


\section{Introduction}

Metal ion complexation on the surface or in the interior of biomolecules is widespread in nature, which has provided the basis for a lively interest in modeling the underlying interactions in the gas phase. In the domain of peptide complexes, interest in such gas-phase models has led to extensive study of metal-ion amino-acid complexes, giving detailed and precise understanding of the thermochemistry and structures of a number of systems. ${ }^{[1-11]}$ Gas-phase study of complexes involving much larger peptide substrates has become experimentally accessible with the emergence of electrospray ionization, and also computationally accessible with advancing computational tools. However, interpretation of results for large systems is not straightforward. A bottom-up approach is attractive to bridge the gap between small and large systems by working up from amino acid monomers through dipeptides, and then on to larger oligopeptides, up to the limit where detailed understanding will inevitably be submerged by the size and complexity of the systems. The present study follows this strategy in exploring dipeptide systems that can model cation- $\pi$ interactions between peptides and alkali ions. The capability of cation- $\pi$ complexation is provided by phenylalanine, which is the simplest amino acid having the possibility of a cation- $\pi$ interaction in addition to the usual interactions of the ion with the Lewis-basic oxygens and nitrogens. The present results for the two Phe-containing dipeptide substrates explored here, PheAla and AlaPhe, have many features in common with previous work on $\mathrm{M}^{+} \mathrm{Ala}{ }^{[12]}$ and $\mathrm{M}^{+} \mathrm{Phe}^{[7,8,13-}$ ${ }^{16]}$ complexes; the outstanding new feature introduced in progressing to the dipeptides is that the amide oxygen binding site appears for the first time, and turns out to be a dominant feature for complexation. 
The thermochemistry and structures of the monomer complexes $\mathrm{Na}^{+} \mathrm{Ala}, \mathrm{K}^{+} \mathrm{Ala}$, $\mathrm{Na}^{+} \mathrm{Phe}$ and $\mathrm{K}^{+} \mathrm{Phe}$ have all been worked on in numerous experimental and computational studies. Recently, the tools for study of gas-phase complexes like these have been enhanced by the infrared (IR) spectroscopic capabilities given by coupling a mass spectrometer to a high-intensity broadly tunable IR light source. The new light sources making this possible include benchtop OPO systems and larger-scale free-electron laser (FEL) facilities. Examples of recent work on peptides include OPO laser studies ${ }^{[9,17-19]}$, and FEL studies using the FELIX (free electron laser for infrared experiments) FEL ${ }^{[20]}$ and the CLIO FEL. ${ }^{[21]}$ In these studies the IR spectrum of the complex is viewed in an "action spectroscopy" mode, in which the extent of IR multiple-photon dissociation (IRMPD) is plotted as a function of photon wavelength.

Numerous computational studies have appeared on complexes of amino acids, including Ala and Phe, for example Refs. ${ }^{[8,13,22,23]}$. Experimentally, sodium and/or potassium ion complexes of both $\mathrm{Ala}^{[12]}$ and $\mathrm{Phe}^{[16]}$ have been characterized by IRMPD spectroscopy, and we can also note examples of structural studies using this technique with other amino acid complexes. ${ }^{[1,9,24]}$ The recent IRMPD spectroscopic study of $\mathrm{M}^{+}$Trp complexes ${ }^{[25]}$ is particularly helpful in interpretation of complexes involving cation- $\pi$ interactions, through the characterization of the mixtures of conformers present in the Trp systems.

\section{Experimental and Computational}

IR spectroscopy. The experimental apparatus, ${ }^{[26,27]}$ methods and protocols were similar to previous work with alkali complexes of amino acids. ${ }^{[25]}$ Solutions of $1 \mathrm{mM}$ dipeptide 
with $1 \mathrm{mM} \mathrm{MCl}$ (where $\mathrm{M}=\mathrm{Na}$ or $\mathrm{K}$ ) were made up in $80 \% \mathrm{MeOH}$ and $20 \% \mathrm{H}_{2} \mathrm{O}$. The metal cation-dipeptide complexes were generated by electrospray ionization (ESI) and accumulated with collisional cooling for 1-2 s in a hexapole, following which they were transferred to the Penning trap of the Fourier transform ion cyclotron resonance (FT-ICR) mass spectrometer. Ions were captured in the trap with minimal collisional excitation by a field-switching approach in the transfer octopole. ${ }^{[7]}$ The ion of interest was mass isolated and then irradiated with 10 macropulses from the FELIX laser to induce IR multiple photon dissociation (IRMPD).

While the IRMPD spectrum is not identical to a linear absorption spectrum, the assumption that the IRMPD yield is linearly proportional to the IR absorption intensity has been considered to be a useful approximation, ${ }^{[28]}$ making it possible to view the IRMPD spectrum as a reflection of the true IR absorption spectrum. For the $\mathrm{K}^{+}$ complexes, the photofragment ion was $\mathrm{K}^{+}$. For the $\mathrm{Na}^{+}$complexes, some photofragment $\mathrm{Na}^{+}$was observed, but in addition a major dissociation channel was $\mathrm{m} / \mathrm{z} 188$, loss of 71 Daltons. The nature of this rearrangement fragmentation process was not clarified. No marked difference was observed in the IRMPD spectra of the two channels of the sodium ion complexes, and their intensities were summed.

Conformation labeling. The chelation patterns discussed here are specified by a uniform labeling format. The five identifiable binding sites are the ring $\pi$ system (R), the amide oxygen $\left(\mathrm{O}_{\mathrm{a}}\right)$, the carboxyl carbonyl oxygen $\left(\mathrm{O}_{\mathrm{t}}\right)$, the hydroxyl oxygen $(\mathrm{OH})$, and the $\mathrm{N}$ terminal nitrogen $\left(\mathrm{N}_{\mathrm{t}}\right)$. For labeling the ring-chelated complexes, we have encoded their arrangement using a conventional ordering of the ligands, by placing the metal above the ring, looking down on the complex, and ordering the ligands counter-clockwise. In the 
non-ring-chelated structures our encoding scheme indicates the identities but not the arrangement of the chelating ligands. In presenting specific examples of the various conformations, we have also used a systematic letter classification of the chelation patterns (without regard to the order of the ligands) as follows: A for $\mathrm{RO}_{\mathrm{a}} \mathrm{O}_{\mathrm{t}}$; $\mathrm{B}$ for $\mathrm{RO}_{a} \mathrm{~N}_{t} ; \mathrm{C}$ for $\mathrm{O}_{\mathrm{a}} \mathrm{O}_{t}$; D for $\mathrm{O}_{\mathrm{a}} \mathrm{N}_{t} \mathrm{O}_{t}$; E for four-fold chelation; $\mathrm{F}$ for $\mathrm{RO}_{\mathrm{a}} \mathrm{OH}$; G for $\mathrm{RN}_{t} \mathrm{OH}$; $\mathrm{H}$ for $\mathrm{RO}_{\mathrm{t}} \mathrm{N}_{\mathrm{t}}$. Finally, an asterisk is appended when the carboxyl $\mathrm{OH}$ is in the exo conformation. Thus for example a fully named example conformation of $\mathrm{K}^{+}$PheAla would be $\left[\mathrm{KFA} \mathrm{A} 4 * \mathrm{RO}_{\mathrm{a}} \mathrm{O}_{\mathrm{t}}\right.$, whose structure appears in Fig. S4.

Choice of DFT Functional. The B3LYP functional has been widely used, and generally considered satisfactory, for alkali ion complexes. Two alternatives are worthy of mention. The BP86 functional has been recommended as giving slightly more accurate absolute binding energies for $\mathrm{Na}^{+}$complexes, ${ }^{33}$ but it gives results quite similar to B3LYP in most respects, has not been suggested as being superior in terms of cation- $\pi$ binding energetics, and was not used here. For complexes involving transition metals binding to aromatic ligands, it has been suggested that the MPW1PW91 functional is more accurate than B3LYP in the energetic comparision of $\pi$-binding sites with other types of sites, and specifically that B3LYP underestimates the strength of $\pi$-ring binding. ${ }^{[29,30]}$ Such an advantage for MPW1PW91 has not been suggested for alkali metal ion complexes, but it was decided to try it in this context, and accordingly the thermochemistry was calculated using both functionals for comparison. As described below, the comparison of functionals showed a small but significant difference in the description of the ring chelation energy, and there was some indication that MPW1PW91 was more accurate. Accordingly, all of the thermochemical considerations were approached using MPW1PW91 enthalpies, while the spectra were calculated using B3LYP for consistency 
with previous work on similar systems. Spectra calculated with MPW1PW91 have not been found to differ very much from B3LYP.

Conformation searching and energy calculations. The conformation space of the complexes was searched quite widely, although no fully satisfactory, comprehensive search method was found. It is expected that all of the good candidates for the ground state of each complex were located, and that representatives of the most stable conformational patterns were found.

Initial searches were Molecular Mechanics (MM) surveys using the Amber99 force field (implemented in the HyperChem 7.5 search engine). Using a usage-directed variation of initial conformations, about 1000 initial structures seemed to be sufficient to locate all the good conformations, yielded about 300 candidate structures within 20 $\mathrm{kJ} / \mathrm{mol}$ of the most stable one, including duplicates. After eliminating obvious duplicates, the candidates were refined at the level of HF/STO-3G. However, the Amber force field did not do a good job with these cation- $\pi$ chelating systems, and numerous reasonable structures were missed in these searches. Additional searches were made directly using HF/STO-3G calculations for energy screening at the $20 \mathrm{~kJ} / \mathrm{mol}$ cutoff level, which uncovered additional candidate structures. This direct HF searching was expensive, and only about a hundred trial geometries were calculated for each complex, which was not sufficient to ensure full coverage of the conformation space. As a third approach, it was hoped that a semiempirical HF method might provide sufficiently accurate energies for comprehensive conformation searching in a reasonable time, but the common semiempirical parametrizations (AM1, PM3, ZINDO) were found to give poor energetics and structures for these cation- $\pi$ systems, and gave no useful results. 
The combined sets of conformations obtained from the MM and HF searches were refined with the higher level DFT calculations, resulting in the sets of low-energy conformations described below. All the energies were calculated with DFT/MPW1PW91, $(6-31+G(d, p))$. For each complex, the three or four most stable conformations were compared using a larger basis, $(6-311+\mathrm{G}(2 \mathrm{df}, 2 \mathrm{pd}))$. These larger-basis calculations generally gave less than $1 \mathrm{~kJ} / \mathrm{mol}$ change in relative energies compared with the lowerlevel DFT calculations, and did not affect the predictions of the ground states, so it was considered that the level of basis set was high enough that the accuracy was not basis-set limited. Thermal corrections to the enthalpies from $0 \mathrm{~K}$ to $298 \mathrm{~K}$ were made, but were less than $1 \mathrm{~kJ} / \mathrm{mol}$. BSSE corrections to DFT in systems similar to these are consistently found to be small and reasonably constant at the $6-31+\mathrm{G}(\mathrm{d}, \mathrm{p})$ level, and were not considered worth the effort of calculation for the purposes of the present study. In the DFT calculations of small model systems described below, a constant value of $4 \mathrm{~kJ} / \mathrm{mol}$ was subtracted from all the raw DFT binding energies as a rough correction for BSSE, vibrational zero point energies (ZPE), and thermal corrections from zero $\mathrm{K}$ to room temperature. The MP2 calculations were done with counterpoise BSSE corrections, and a constant value of $2 \mathrm{kcal} / \mathrm{mol}$ was subtracted to approximate the $\mathrm{ZPE}$ and thermal corrections.

Stabilities of the calculated complexes were assessed using free energy values, where the entropic constributions were assigned from the vibrational entropy corresponding to the calculated frequencies. As will be seen below (Table 2) the thermal and entropic corrections can affect the predicted relative stabilities of different conformers by several $\mathrm{kJ} / \mathrm{mol}$ in some cases. Full vibrational calculations at the DFT/B3LYP $(6-31+G(d, p))$ level were done on all the conformations considered to be 
possible candidates for the actual ground-state structures, as well a some other higherenergy structures having points of interest. All of the calculated DFT structures, and all of the vibrational calculations, are reported in the Supplementary Material.

Assigning a precise scaling factor to the computed vibrational frequencies.is somewhat uncertain. Recent B3LYP calculations of systems involving amino acids and alkali ions have found best fits using factors of $0.960,0.975$ and 0.987 , but none has used exactly the same basis as the present work. The value of 0.960 , using a substantially smaller basis, is probably too low for the present protocol. The value of 0.975 , assigned for Trp complexes using a larger basis than the present one ${ }^{[25]}$, is probably the most closely transferable to the present work. This value, which was judged to give as good fits as any to the spectra, was used throughout the present work. We have taken care not to make spectroscopic interpretations that are not robust within a range of scale factors from perhaps 0.960 to 0.985 . All quantum calculations used the Gaussian03W package. ${ }^{[31]}$

\section{Results and Discussion}

Model systems and chelation expectations. The dipeptides are a useful transition between the well studied binding chemistry of the isolated amino acids, and the study, much less developed, of metal-ion binding to oligopeptide and protein systems. These dipeptides, although they are still simple enough for detailed structural investigation and computation, nevertheless offer the full set of possible chelation sites for a metal ion that recur in larger oligopeptides that contain Phe. A useful starting point can be a rough assessment of the relative binding strengths of the different sites available in the 
dipeptides constructed from Ala and Phe, in which it is assumed for the moment that there are no steric costs of achieving optimal chelation of the metal ion, and that we can ignore any hydrogen-bonding or other intramolecular interactions other than the direct interaction with the metal ion. One way to survey such idealized binding-site characteristics is via small model ligands having isolated binding sites. Although metalion affinities are experimentally known for some useful small model systems (for example, Ref. 32), they are not consistently available or consistently reliable. Rather than trying to use experimental values, we made a set of moderately good calculations on the following model set, which display the chemical environments present in these dipeptides, and where the structures are chosen to contain well defined single chelation points. Model calculations were chosen such that no major change of conformation or multiple chelation accompanies complexation. These systems also have roughly similar sizes in order to equalize polarization effects (Table 1). The model predictions are displayed pictorially in Fig. 1.

Values calculated with the MPW1PW91/6-31+G(d,p) protocol are used in the following discussion, but it is of interest to compare this protocol with the MP2 protocol used by Hoyau et al. (MP2/6-311+g(2d,2p)//MP2/6-31 $\left.\mathrm{g}^{*}\right)$ in their survey of $\mathrm{Na}^{+}$ affinities. Both sets of values are given in Table 1. It can be seen that the DFT and MP2 protocols yield quite similar results for the $\mathrm{K}^{+}$complexes, while the differences for the $\mathrm{Na}^{+}$complexes are larger (up to $11 \mathrm{~kJ} / \mathrm{mol}$ ). Similar to what was found by Armentrout and Rodgers for the B3LYP functional, our DFT results for sodium ion are a few $\mathrm{kJ} / \mathrm{mol}$ higher than MP2, and are somewhat scattered versus MP2. ${ }^{[33]}$ (They found that either MP2 or DFT/B3P86 gave somewhat better results for $\mathrm{Na}^{+}$; all of these methods give results entirely adequate for the present purposes.) No conclusion seems warranted about 
the accuracy of the calculations for $\mathrm{K}^{+}$complexes. The observations and conclusions given below about the binding sites are equally valid using either DFT or MP2 binding energies. 
Table 1. Metal-ion bond dissociation energies of small model compounds containing the five Lewis-basic chelation sites having interest for the present dipeptides. Values $(\mathrm{kJ} / \mathrm{mol})$ calculated at the DFT MPW1PW91/6-311+G(d,p) level. For comparison, values are also given using an MP2 protocol (MP2/6-311+g(2d,2p)//MP2/6-31g*). Values in $\mathrm{kJ} / \mathrm{mol}$, with approximate corrections for $298 \mathrm{~K}$ thermal effects, BSSE and zero-point energies (see text)

\begin{tabular}{|l|l|c|c|c|c|}
\hline \multirow{2}{*}{ Type of site } & \multirow{2}{*}{ Model compound } & \multicolumn{2}{|c|}{$\mathrm{Na}^{+}$} & \multicolumn{2}{c|}{$\mathrm{K}^{+}$} \\
\cline { 3 - 6 } & & DFT & MP2 & DFT & MP2 \\
\hline Amide $\mathrm{C}=\mathrm{O}\left(\mathrm{O}_{\mathrm{a}}\right)$ & N-methylacetamide & 165 & 154 & 125 & 123 \\
\hline Acid $\mathrm{C}=\mathrm{O}\left(\mathrm{O}_{\mathrm{t}}\right)$ & Acetic acid & 118 & 108 & 84 & 83 \\
\hline Ring $(\mathrm{R})$ & Benzene & 99 & 88 & 69 & 72 \\
\hline Terminal N $\left(\mathrm{N}_{\mathrm{t}}\right)$ & Aminoacetone & 96 & 90 & 61 & 63 \\
\hline Acid $\mathrm{OH}(\mathrm{OH})$ & Acetic acid & 55 & 53 & 31 & 35 \\
\hline
\end{tabular}




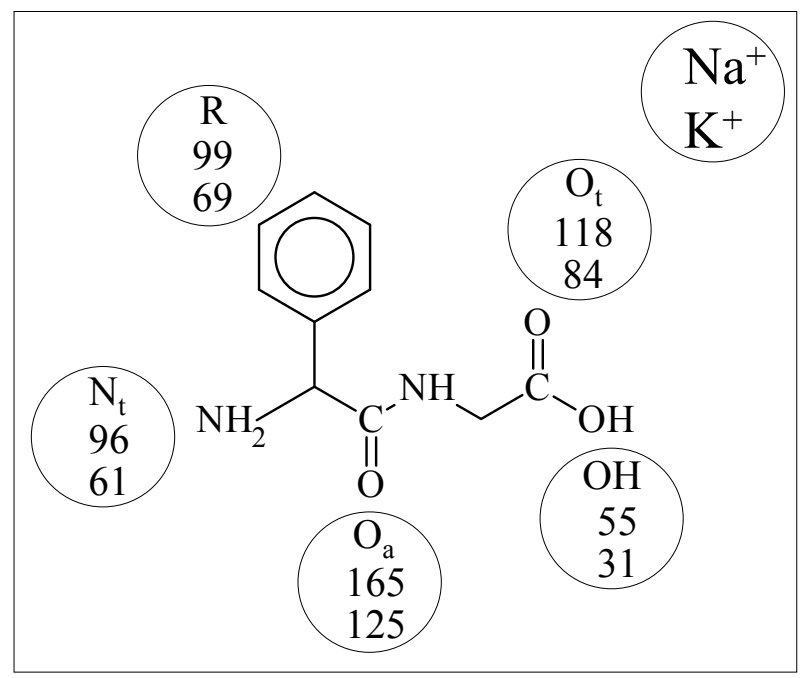

Fig. 1. Calculated metal ion affinities of dipeptide binding sites $(\mathrm{kJ} / \mathrm{mol})$ derived from calculations of simple model systems (Table 1). (DFT MPW1PW91/6-311+G(d,p)).

The models indicate that the amide oxygen site $\left(\mathrm{O}_{\mathrm{a}}\right)$ is highly favored and should be metalated consistently. It is thus not surprising that the calculations of Wang et al. found that polyglycines and polyalanines as high as the tetrapeptides commonly favor chelation by all the available CO groups prior to populating the $\mathrm{N}_{t}$ binding site. ${ }^{[34]}$ However, it is slightly surprising that for tetraalanine, where they found two nearly equal lowest-energy conformations, one of these conformations has one of the three $\mathrm{O}_{\mathrm{a}}$ sites unchelated while the $\mathrm{O}_{t}$ site is chelated. For various dipeptides where calculations have been reported, for example Refs. 34-41, the $\mathrm{O}_{\mathrm{a}}$ site is always chelated in the low-energy conformers, as expected.

The terminal carboxyl $\mathrm{C}=\mathrm{O}\left(\mathrm{O}_{\mathrm{t}}\right)$ is somewhat favored over the remaining sites. The ring $(\mathrm{R})$ is not very different from the $\mathrm{NH}_{2}$ site $\left(\mathrm{N}_{\mathrm{t}}\right)$ in binding affinity, and these two sites could be competitive, although the MPW1PW91 results indicate a small preference for the ring over the $\mathrm{NH}_{2}$. The hydroxyl site $(\mathrm{OH})$ is much less favorable, and should not 
be a competitive binding site. The amide nitrogen does not offer a favorable chelation site; attempts to model a metal ion near this nitrogen resulted in spontaneous migration of the metal to the nearby oxygen. It should be stressed that these intrinsic relative site affinities are only a starting point, and the relative stabilities of actual conformers of peptide complexes having various chelation patterns can be drastically altered by steric strain, intramolecular H-bonding, and other perturbations.

Moision and Armentrout have applied a similar approach to analyzing metal-ion $\left(\mathrm{Na}^{+}\right.$and $\left.\mathrm{K}^{+}\right)$complexes with glycine, ${ }^{[42,43]}$ in which a set of single-site and bidentate model ligands was used to generate single-site metal-ion affinities. They achieve detailed dissections of various factors acting to determine the structures of the complexes. Their studies are not easily compared with the present work, however, because they used a different set of model complexes not well suited to dipeptide modeling. Their modeling suggested that $\mathrm{Na}^{+}$has a significant enhancement in the relative affinity of the nitrogen site compared with $\mathrm{K}^{+}$, which they considered responsible for systematic $\mathrm{Na}^{+} / \mathrm{K}^{+}$ differences in the stabilities of various chelation patterns. However, our model set did not suggest a similar effect, nor did our calculated comparisons of chelation schemes show any obvious favoring of nitrogen chelation for $\mathrm{Na}^{+}$.

The sodium complexes of GlyHis and HisGly have been studied computationally ${ }^{[37]}$, and may provide interesting parallels to the present results, since the His side chain can function as a $\pi$-chelating ligand, although edge-chelation of the metal ion by one of the ring nitrogens is more favorable when sterically feasible. Thus the $\mathrm{N}^{\varepsilon}-\mathrm{H}$ tautomer of both isomers, in which edge-on interaction of $\mathrm{Na}^{+}$with the imidazole ring is possible, provides the most stable conformations. In the $\mathrm{N}^{\delta}-\mathrm{H}$ tautomers, where the edge-on 
interaction is not possible, the imidazole ring gives cation- $\pi$ chelated conformations, but their stability is lower by $\sim 40 \mathrm{~kJ} / \mathrm{mol}$ than the best $\mathrm{N}^{\varepsilon}-\mathrm{H}$ structures.

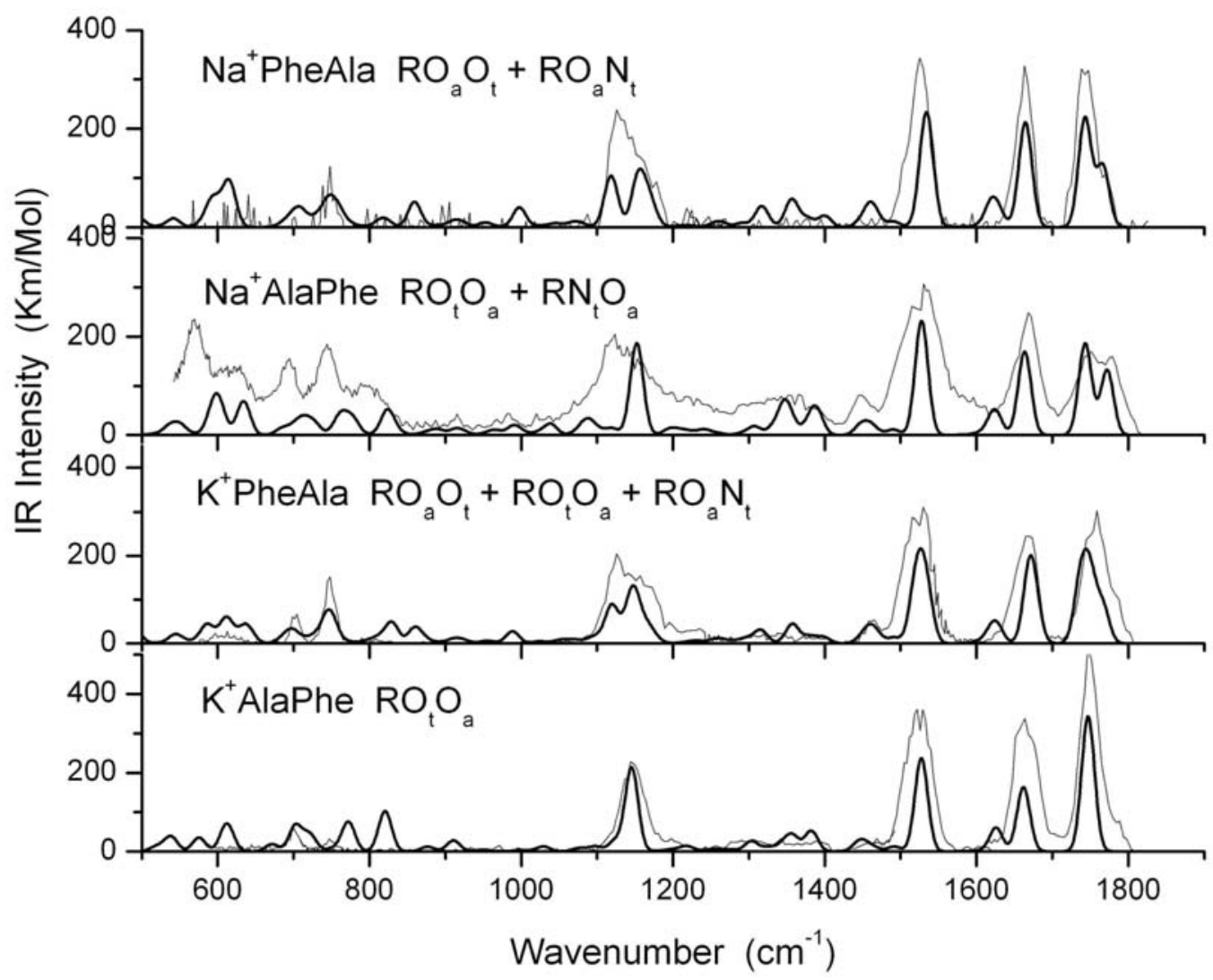

Fig. 2. IRMPD spectra of the four complexes (light lines) along with the calculated spectrum of the most stable conformer, or of a mixture of conformers of similar stability (dark lines). For a mixture, the theoretical spectra of the relative conformers are simply co-added.

The IRMPD spectra are shown in Fig. 2. As is discussed in detail below, the experimental spectra are accompanied by computed spectra representing either the most 
stable conformation, or a mixture of low-energy conformations illustrating one out of many possible mixed populations giving acceptable fits to the observed spectrum. The quality of the spectra is sufficiently good to form the basis for detailed consideration of the structures of the complexes. A useful starting point is the comparison of the four spectra, which are seen to be very similar in the number, positions and intensities of the major peaks. The close similarity of the spectra of the four systems makes it attractive to start with the hypothesis that the chelation pattern is the same. The detailed matchup of the spectra with calculated structures described below indicates that the overall most favored structural motif has threefold chelation $\mathrm{RO}_{\mathrm{a}} \mathrm{O}_{\mathrm{t}}$ or $\mathrm{RO}_{\mathrm{t}} \mathrm{O}_{\mathrm{a}}$, with the metal ion being chelated with the ring and with the two carbonyl oxygen atoms. If forced to choose a single chelation pattern, this would be the most attractive. However, the three-fold chelation $\mathrm{RO}_{\mathrm{a}} \mathrm{N}_{\mathrm{t}}$ or $\mathrm{RN}_{\mathrm{t}} \mathrm{O}_{\mathrm{a}}$ involving the amide oxygen, the ring, and the terminal nitrogen is nearly as good, and is a serious possibility for making up part of the ion populations. Conformations in which the ring is not chelated are less attractive, but detailed examination shows that some contribution of such structures also can not be ruled out. Overall, the agreement of the observed spectra with the computational expectations is impressive.

Structural conclusions from spectra. There are hundreds of possible conformations of each of these complexes, many of which are stable local minima on the potential energy surface. To narrow these down and draw structural conclusions, it is necessary to compare the spectra with calculated spectra of the energetically reasonable possibilities, combining the criteria of (1) calculated stability and (2) match to the calculated spectrum, to identify one or several conformations that make up the population of ions in the trap. The structure search methods used were not fully exhaustive, but were sufficiently broad 
so that we hope we have located all of the conformations lying within a few $\mathrm{kJ} / \mathrm{mol}$ of the most stable one, and have identified the chelation modes most likely to be contributors to the populations. Fig. 2 shows the fits obtained from the lowest energy conformer, or a mixture of conformers of similarly low energy, for each of the four spectra.

Out of the large number of conformations found by broad searching procedures, we carried out high-level optimization and energy calculations on those that seemed most likely to be close to the ground state, also including representative examples of other reasonably favorable chelation patterns. This set of example conformations is shown in Table 2. In Figs. 3 and 4 are shown representatives of the various chelation patterns calculated, and in Figs. S1 to S4 of the Supplementrary Material are shown the actual structures of all the conformations. As indicated in Table 2, many of the chelation patterns gave multiple low-energy conformations in our searches, and in addition, many other conformations exist but were not considered likely to be stable enough to warrant high-level calculation. 
Table 2. Calculated thermochemistry of low-energy complex conformations. Values $(\mathrm{kJ} / \mathrm{mol})$ are given in the form $\left[\mathrm{Na}^{+}\right.$complex $] /\left[\mathrm{K}^{+}\right.$complex $]$. Calculations are DFT/MPW1PW91 except for the last column, which is DFT/B3LYP.

\begin{tabular}{|c|c|c|c|c|}
\hline & Chelation & $\Delta \mathrm{H} 0 \mathrm{~K}$ & $\Delta \mathrm{G} 298 \mathrm{~K}$ & $\Delta \mathrm{G}$ B3LYP \\
\hline \multicolumn{5}{|c|}{$\mathbf{M}^{+}$PheAla } \\
\hline $\mathrm{A} 1$ & $\mathrm{RO}_{\mathrm{a}} \mathrm{O}_{\mathrm{t}}$ & $0 / 0$ & $0 / 0$ & $0 / 0$ \\
\hline $\mathrm{B} 1$ & $\mathrm{RO}_{\mathrm{a}} \mathrm{N}_{\mathrm{t}}$ & $7 / 4$ & $3 / 2$ & $4 / 4$ \\
\hline $\mathrm{A} 2$ & $\mathrm{RO}_{\mathrm{t}} \mathrm{O}_{\mathrm{a}}$ & $8 / 2$ & $6 / 0$ & $7 / 1$ \\
\hline $\mathrm{C} 1$ & $\mathrm{O}_{\mathrm{a}} \mathrm{O}_{\mathrm{t}}$ & $16 / 7$ & $7 / 1$ & $4 /-4$ \\
\hline $\mathrm{A} 3$ & $\mathrm{RO}_{\mathrm{t}} \mathrm{O}_{\mathrm{a}}$ & $16 /$ & $13 /$ & $13 /$ \\
\hline D1 & $\mathrm{O}_{\mathrm{a}} \mathrm{O}_{\mathrm{t}} \mathrm{N}_{\mathrm{t}}$ & $20 / 13$ & $17 / 11$ & $17 / 12$ \\
\hline D2 & $\mathrm{O}_{\mathrm{a}} \mathrm{O}_{\mathrm{t}} \mathrm{N}_{\mathrm{t}}$ & $/ 18$ & $/ 15$ & $/ 13$ \\
\hline $\mathrm{A} 2 *$ & $\mathrm{RO}_{\mathrm{t}} \mathrm{O}_{\mathrm{a}}{ }^{*}$ & $/ 19$ & $/ 17$ & $/ 19$ \\
\hline E1 & $\mathrm{RO}_{\mathrm{t}} \mathrm{O}_{\mathrm{a}} \mathrm{N}_{\mathrm{t}}$ & $23 / 9$ & $22 / 9$ & $24 / 12$ \\
\hline $\mathrm{A} 1 *$ & $\mathrm{RO}_{\mathrm{a}} \mathrm{O}_{\mathrm{t}}{ }^{*}$ & $23 / 19$ & $21 / 17$ & $22 / 19$ \\
\hline E2 & $\mathrm{RO}_{\mathrm{t}} \mathrm{O}_{\mathrm{a}} \mathrm{N}_{\mathrm{t}}$ & $28 /$ & $26 /$ & $27 /$ \\
\hline $\mathrm{C} 2$ & $\mathrm{O}_{\mathrm{a}} \mathrm{O}_{\mathrm{t}}$ & $38 / 27$ & $34 / 15$ & $28 / 13$ \\
\hline F1 & $\mathrm{RO}_{\mathrm{a}} \mathrm{OH}$ & $42 / 34$ & $39 / 33$ & $41 / 33$ \\
\hline \multicolumn{5}{|c|}{$\mathbf{M}^{+}$AlaPhe } \\
\hline $\mathrm{A} 1$ & $\mathrm{RO}_{\mathrm{t}} \mathrm{O}_{\mathrm{a}}$ & $0 / 0$ & $0 / 0$ & $0 / 0$ \\
\hline B1 & $\mathrm{RN}_{\mathrm{t}} \mathrm{O}_{\mathrm{a}}$ & $4 / 9$ & $6 / 10$ & $5 / 5$ \\
\hline D1 & $\mathrm{O}_{\mathrm{a}} \mathrm{O}_{\mathrm{t}} \mathrm{N}_{\mathrm{t}}$ & $21 / 23$ & $22 / 23$ & $19 / 14$ \\
\hline $\mathrm{D} 1 *$ & $\mathrm{O}_{\mathrm{a}} \mathrm{O}_{\mathrm{t}} \mathrm{N}_{\mathrm{t}}{ }^{*}$ & $18 / 19$ & $19 / 18$ & $18 / 16$ \\
\hline $\mathrm{C} 1$ & $\mathrm{O}_{\mathrm{a}} \mathrm{O}_{\mathrm{t}}$ & $18 / 15$ & $15 / 12$ & $11 / 3$ \\
\hline $\mathrm{C} 1 *$ & $\mathrm{O}_{\mathrm{a}} \mathrm{O}_{\mathrm{t}}{ }^{*}$ & $18 / 13$ & $15 / 10$ & $15 / 6$ \\
\hline $\mathrm{B} 2$ & $\mathrm{RO}_{\mathrm{t}} \mathrm{N}_{\mathrm{t}}$ & $24 / 27$ & $26 / 30$ & $27 / 27$ \\
\hline $\mathrm{A} 2$ & $\mathrm{RO}_{\mathrm{t}} \mathrm{O}_{\mathrm{a}}$ & $29 / 28$ & $28 / 29$ & $27 / 25$ \\
\hline F1 & $\mathrm{RO}_{\mathrm{a}} \mathrm{OH}$ & $28 / 28$ & $29 / 34$ & $30 / 32$ \\
\hline B3 & $\mathrm{RO}_{\mathrm{t}} \mathrm{N}_{\mathrm{t}}$ & 134 & $/ 38$ & 139 \\
\hline B4 & $\mathrm{RO}_{\mathrm{a}} \mathrm{N}_{\mathrm{t}}$ & 140 & $/ 43$ & 136 \\
\hline G1 & $\mathrm{RN}_{\mathrm{t}} \mathrm{OH}$ & 159 & $/ 63$ & 160 \\
\hline
\end{tabular}




\section{$\mathrm{K}^{+}$PheAla}
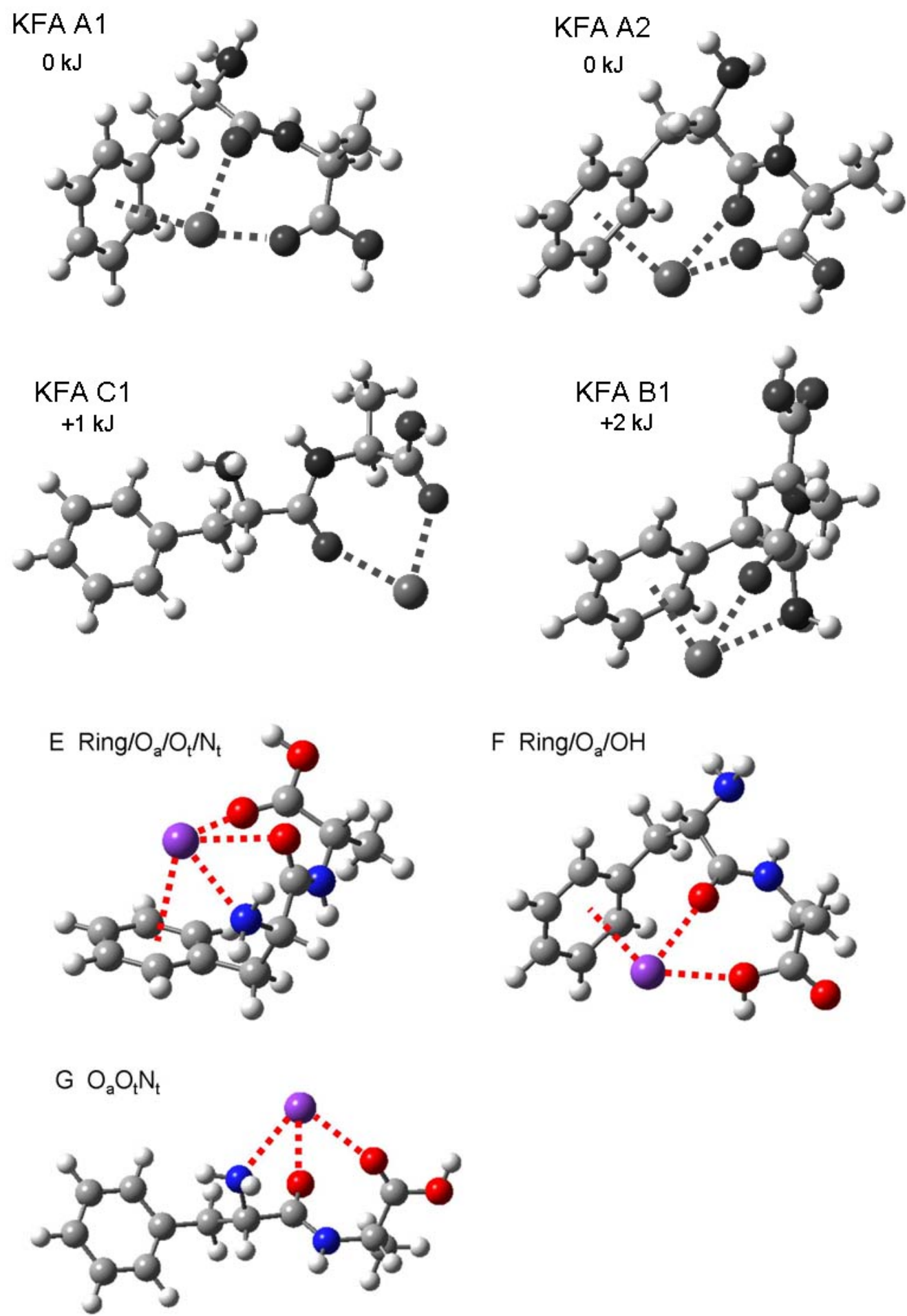
Fig. 3. Computed favorable chelation patterns for the PheAla complexes.
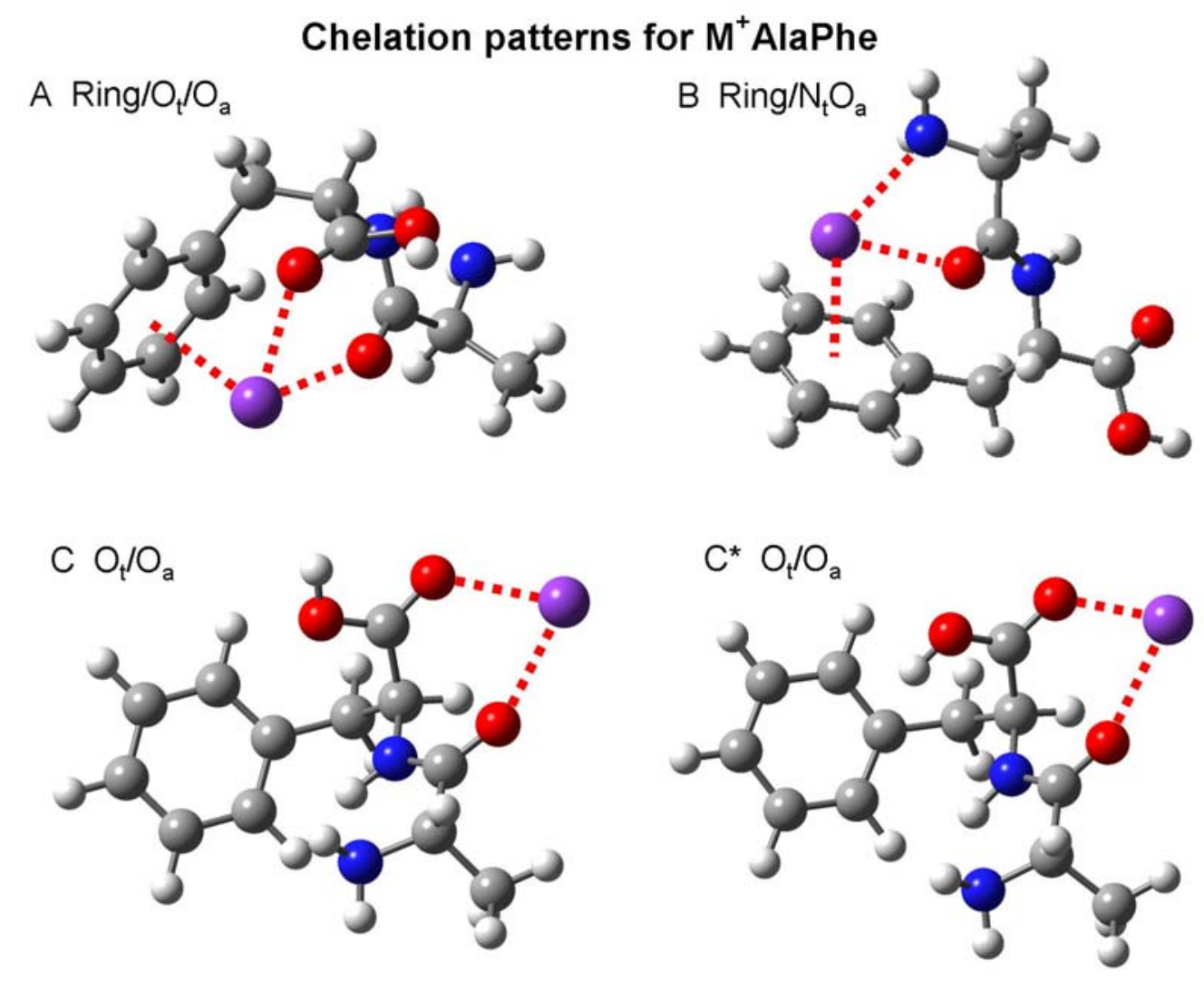

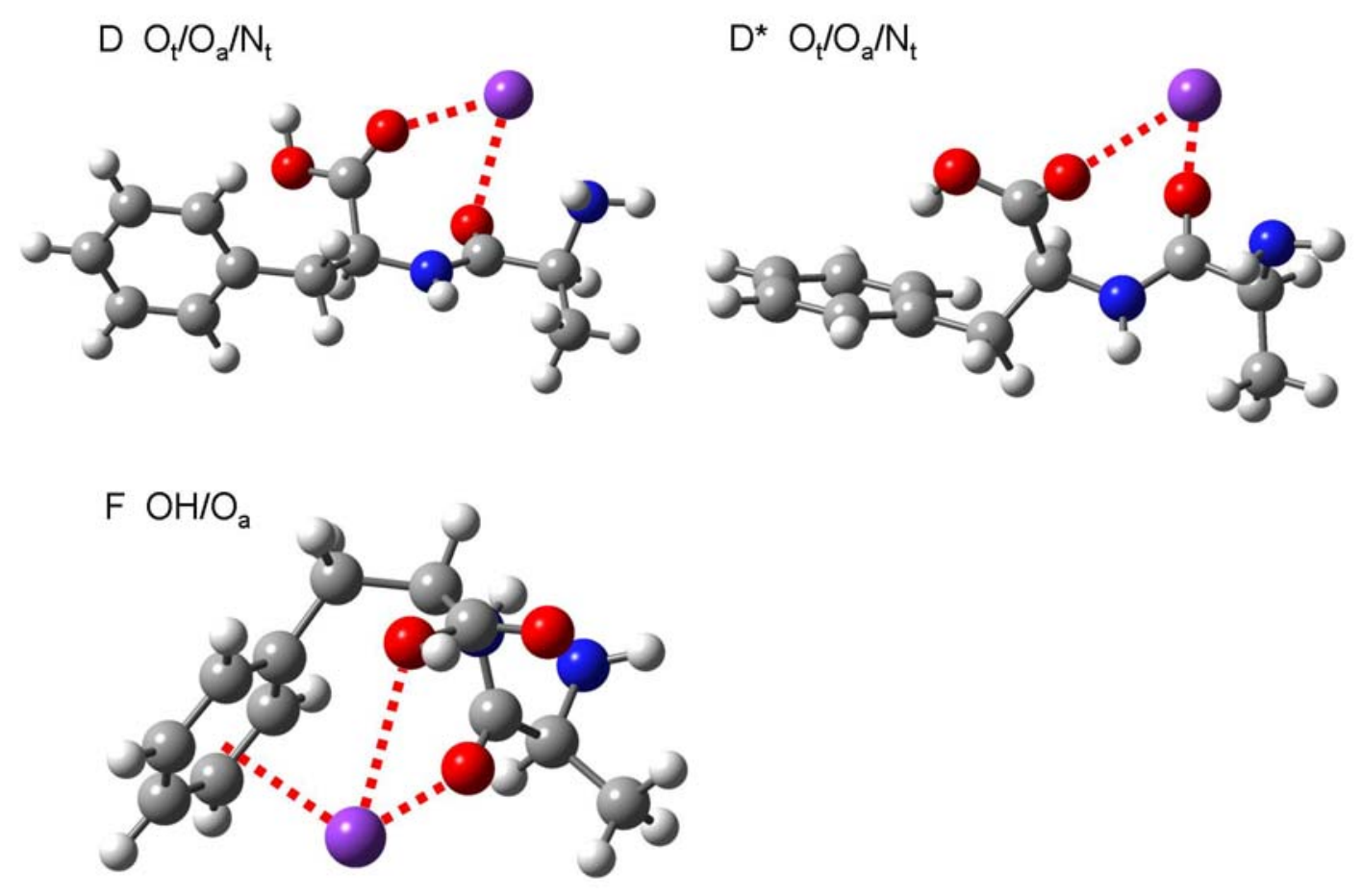

Fig. 4. Computed favorable chelation patterns for the AlaPhe complexes.

Zwitterion possibilities. It has been well established that the IR spectra of metal ion complexes of amino acids provide a clear distinction between the zwitterion (or salt bridge) tautomer and the neutral (or charge solvation) tautomer of the amino acid. The zwitterion form is distinguished by a strong $\mathrm{CO}_{2}{ }^{-}$band between 1650 and $1700 \mathrm{~cm}^{-1}$ as well as a strong $\mathrm{NH}_{3}{ }^{+}$band around $1400 \mathrm{~cm}^{-1}$, while the neutral form gives a strong characteristic $\mathrm{C}=\mathrm{O}$ stretching band between 1700 and $1775 \mathrm{~cm}^{-1}$. The present spectra show the signature $\mathrm{C}=\mathrm{O}$ band at about $1750 \mathrm{~cm}^{-1}$ that is diagnostic for the neutral form of the terminal $\mathrm{COOH}$ group. The absence of any feature in the $1400 \mathrm{~cm}^{-1}$ region indicates a lack of appreciable zwitterion contributions. No conclusion about the possible presence of zwitterion component can be drawn from the presence of the band at $1675 \mathrm{~cm}^{-1}$, since 
this is also the position of the strong amide $\mathrm{N}-\mathrm{H}$ bend that is expected in any case for the dipeptides.

Computationally, no zwitterion structures were found with energies competitive with the favorable charge-solvated isomers. The best configuration for zwitterion stability is commonly found to be a salt-bridge geometry in which the negative charge of the $\mathrm{CO}_{2}^{-}$ is stabilized by proximity to the positive $\mathrm{NH}_{3}{ }^{+}$group as well as the metal ion. Trial zwitterion structures of this type rearranged spontaneously to the neutral form by proton migration from $\mathrm{NH}_{3}{ }^{+}$to $\mathrm{CO}_{2}{ }^{-}$. Since the spectra conclusively rule out predominant zwitterion structures, and since such structures have not been found to be energetically competitive in gas-phase metal-ion complexes with either Ala or Phe monomers, we did not pursue computational investigation of other zwitterion structures.

Configuration of carboxyl OH. The interaction of the hydroxyl with the neighboring carbonyl oxygen is worth around $20 \mathrm{~kJ} / \mathrm{mol}$, as shown by the comparison of the endo (interacting) and exo (non-interacting) conformations. See for example $\mathrm{K}^{+}$PheAla A1 vs A1*; $\mathrm{K}^{+} \mathrm{PheAla}$ A2 vs A2*; $\mathrm{Na}^{+} \mathrm{PheAla}$ A1 vs A1*. These examples with PheAla complexes assess the interaction strength by comparison with the non-interacting forms where the hydrogen has no intramolecular hydrogen bond. A similar endo interaction strength would be anticipated for AlaPhe complexes in the absence of hydrogen bonding. However, with the AlaPhe complexes, the most interesting and most stable exo configurations are those which are able to form an $\mathrm{OH}-\pi$ hydrogen bond with the ring, which compensates the loss of the $\mathrm{OH}^{\cdots} \mathrm{OC}$ interaction in the endo configuration. This $\mathrm{OH}-\pi$ hydrogen bond is sufficiently strong so that the exo and endo conformations are not very different in stability (suggesting an $\mathrm{OH}-\pi$ stabilization also of the order of 20 
kJ/mol). See for example KAlaPhe C1 vs C1*; KAlaPhe D1 vs D1*; NaAlaPhe D1 vs D1*. Such XH- $\pi$ hydrogen bonds are well known structural features of peptides ${ }^{[44]}$. The spectral signature of the exo conformation of the $\mathrm{OH}$ is the shift of the $\mathrm{OH}$ bend from $\sim 1150 \mathrm{~cm}^{-1}$ (endo) to $\sim 1250$ (exo).

The experimental result on this question is clear. The spectra (Fig. 2) show a strong feature at $\sim 1150 \mathrm{~cm}^{-1}$, and no significant peak around $1250 \mathrm{~cm}^{-1}$, which clearly indicates the endo conformation in all cases.

Extent and nature of chelation. Complex conformations of reasonable stability were found with two-fold (C), three-fold (A, B, D, F and G) and four-fold (E) chelation of the metal ion (see Table 2, Figs. 3 and 4 and Figs. S1-S4 for examples). Table 2 indicates that three-fold chelation gives the most stable conformations in each case. However, twofold chelation is able to give nearly equally stable complexes (with respect to relative $\Delta \mathrm{G}^{\prime}$ 's) for $\mathrm{K}^{+}$complexes (as in $\mathrm{K}^{+} \mathrm{AlaPhe} \mathrm{C} 1$ and $\mathrm{K}^{+}$PheAla $\mathrm{C} 1$ ). The fourfold chelated conformations that we located were all substantially less stable than the best structures.

The two-fold chelated conformations without ring chelation (chelation type C) are extended, loose structures with relatively high entropies, as reflected by the fact that their relative free energies (Table 2) are more favorable than their relative enthalpies. Thus the greater conformational flexibility of the two-fold chelation pattern can compensate partially for their generally less favorable chelation enthalpy, compared with the threefold chelated forms, although this compensation is never large enough to make any of them the overall ground state conformation. Surprisingly, the relative entropies of the threefold and fourfold chelated conformations were not very different. We surmise that the steric strain and bond misalignment accompanying the achievement of any of the fourfold chelated conformations results in bond loosening, which counteracts the 
tightening effect of the more constrained fourfold chelated geometries and gives a net similarity of entropies.

As expected from the small-molecule models, all conformations of reasonable stability include $\mathrm{O}_{a}$ chelation. Moreover, the most stable conformations in each case are achieved by chelation of the three ligands predicted by the small-molecule modeling to have the highest metal ion affinities, namely $\mathrm{O}_{\mathrm{a}}, \mathrm{O}_{\mathrm{t}}$ and $\mathrm{R}$. However, Table 2 also indicates that conformations involving $\mathrm{N}_{\mathrm{t}}$ chelation can be very competitive even though the model amino nitrogen has somewhat lower metal-ion affinity than the other three types of isolated sites. Indicative of the limitation of the small-molecule models, the high stability of the $\mathrm{B} 1$ conformations $\left(\mathrm{RO}_{\mathrm{a}} \mathrm{N}_{\mathrm{t}}\right)$ is unexpected from the models, which would suggest that $\mathrm{O}_{t}$ would always chelate in preference to both $\mathrm{R}$ and $\mathrm{N}_{\mathrm{t}}$. As predicted from the models, $\mathrm{OH}$ chelation is not thermodynamically competitive, and the most stable conformations involving this ligand that we found, as indicated in the table, are substantially less stable than the overall best conformations. Thus the model-derived predictions of exceptionally strong chelation by $\mathrm{O}_{\mathrm{a}}$, and exceptionally weak chelation by $\mathrm{OH}$, are found by experiment and by computations to be dominant effects; while the other three chelation sites, $\mathrm{O}_{\mathrm{t}}, \mathrm{N}_{\mathrm{t}}$ and $\mathrm{R}$, can all be competitive chelators, depending on details of steric strain and other secondary intramolecular interactions.

Predicted versus observed spectra. Out of the conformers located in the low-level searches, higher-level DFT calculations were done on those that seem likely to have competitively high stabilities, as well as some less stable conformers of particular interest (Table 2). The predicted IR spectra of many of these are plotted in Figs. 5 to 8, with additional spectra also shown in the Supplementary Material (Figs. S5 to S8). 
Many of the predicted spectral features correspond to vibrational types that are common across all four systems. These recurrent normal modes are described on the calculated A1 spectrum of $\mathrm{K}^{+}$PheAla in Fig. 6.

One general feature is that all calculations predict a feature of varying intensity near $1620 \mathrm{~cm}^{-1}$ corresponding to the $\mathrm{NH}_{2}$ scissoring vibration. Except for the suggestion of a possible small shoulder there for $\mathrm{K}^{+}$AlaPhe, none of the observed spectra show a peak there above the background noise. Evidently this vibration is rather weak for all four systems, which gives an argument against many possible structure assignments for which this feature is predicted to be strong. Another frequent feature in the calculations is a peak corresponding to the $\mathrm{NH}_{2}$ inversion mode of the $\mathrm{NH}_{2}$ group (or the frustrated inversion, in situations where the nitrogen is metal-ion chelated). This mode is predicted with reasonable intensity by harmonic force-field calculations anywhere from 800 to $1100 \mathrm{~cm}^{-}$ ${ }^{1}$ (for example, at $860 \mathrm{~cm}^{-1}$ in Fig. 6, A1). A corresponding peak is not apparent in most of the observed spectra. This mode is thought to be highly anharmonic, and strongly variable in predicted frequency depending on the chelation situation of the terminal nitrogen. In general it is not expected to be well treated by the harmonic vibrational calculations at the present level of theory. Thus the non-appearance of such a peak at the calculated position in the spectra has not been considered as a significant counterindication of a fit.

It had been hoped that the peaks observed in the $550-800 \mathrm{~cm}^{-1}$ region of the spectrum would provide key diagnostic structure indicators, since ring out-of-plane Hbending modes appear in this region, and might be expected to be strong indicators of the state of ring chelation. This hope was generally not borne out. The calculated peaks in this region are generally quite weak, and reliable correlations of distinctive predicted 
peaks with particular patterns of ring chelation did not emerge. Thus no obviously useful information could be ascribed to the rather weak experimental peaks in this region. It can be said that the the best-fit conformational patterns usually provide acceptable fits to the spectra in this region, but many other conformations also give sufficiently good fits.

Further conclusions from the spectroscopy depend on a more detailed look at the spectra for the different dipeptide/metal combinations, which, while similar, are not exactly identical. These details are explored in the following sections.

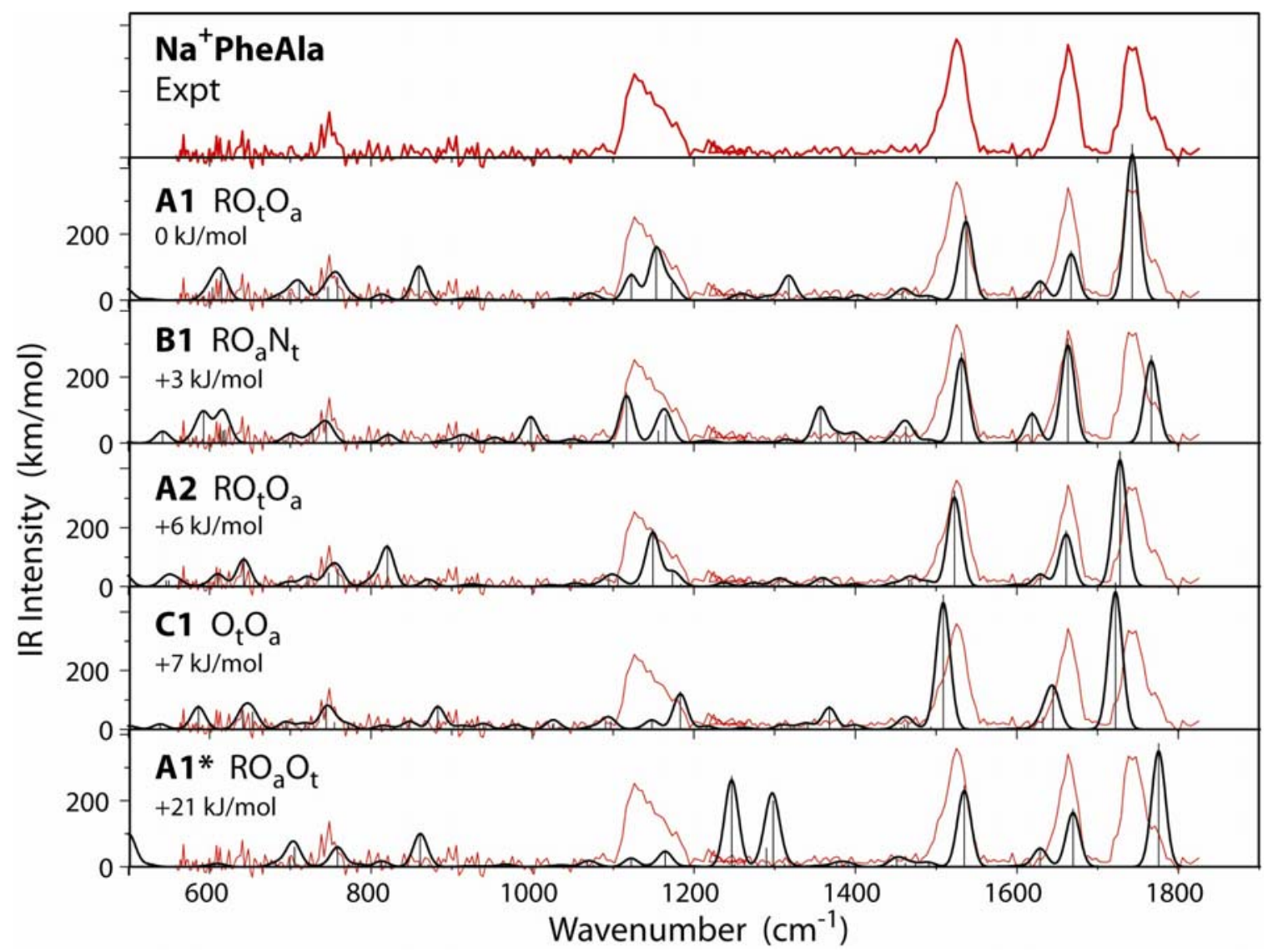

Fig. 5. Experimental spectrum (red) and low-energy conformations (black) of $\mathrm{Na}^{+}$PheAla. (The labeling scheme is described in the text. Note that the asterisk, as in the label of the bottom spectrum, indicates the exo configuration of the carboxyl OH.) 


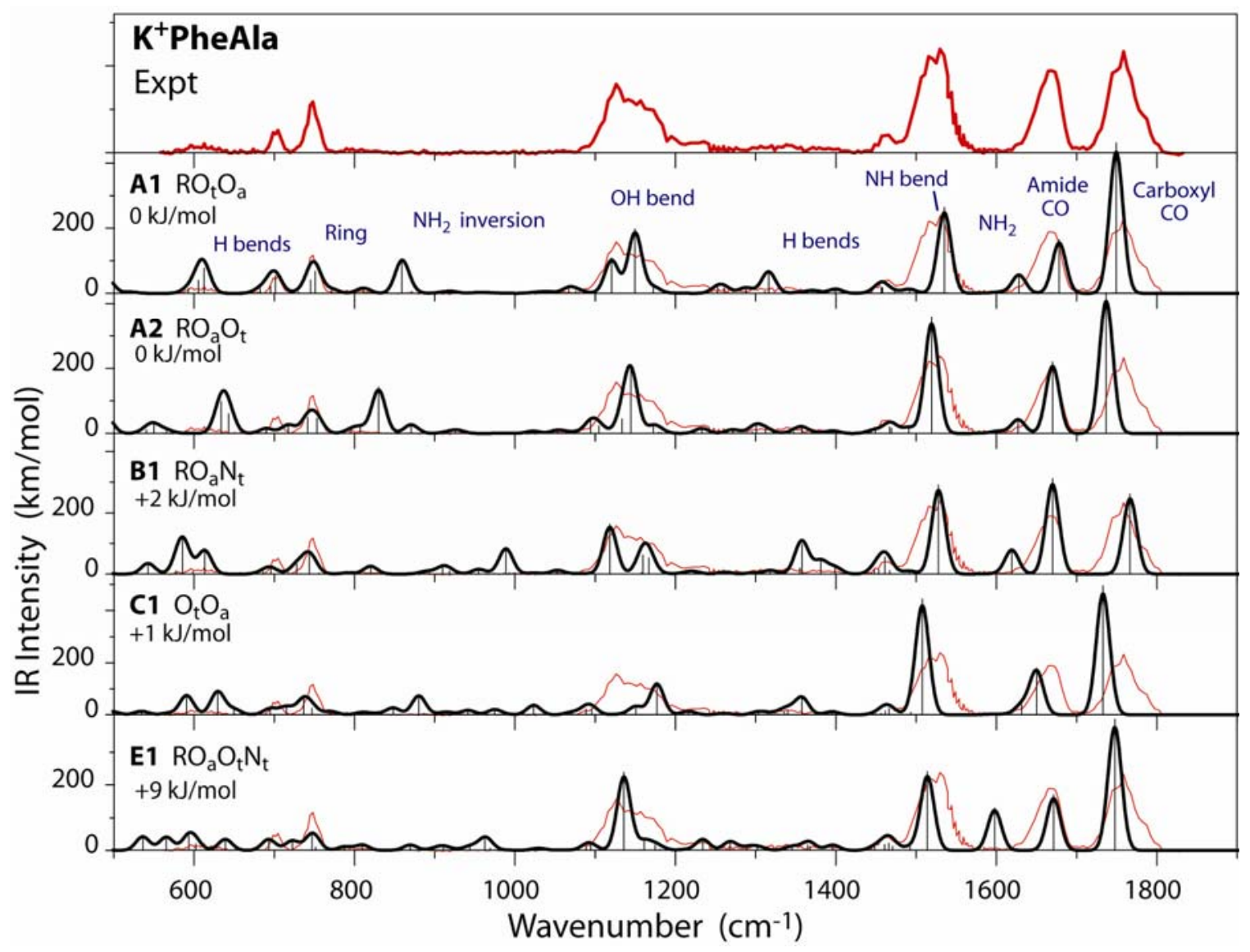

Fig. 6. Experimental spectrum (red) and low-energy conformations (black) of $\mathrm{K}^{+}$PheAla. 


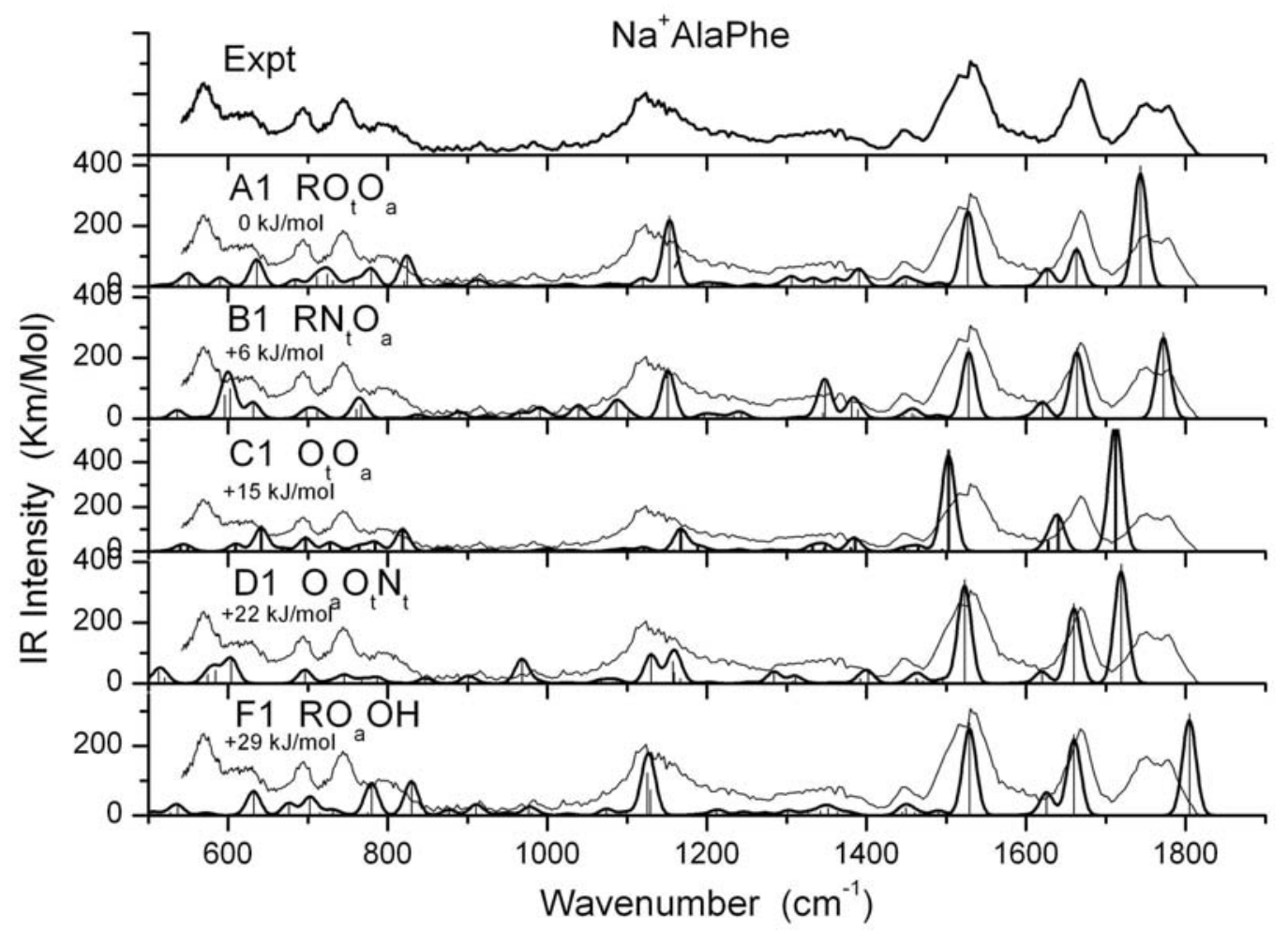

Fig. 7. Experimental spectrum (red) and low-energy conformations (black) of $\mathrm{Na}^{+}$AlaPhe. 


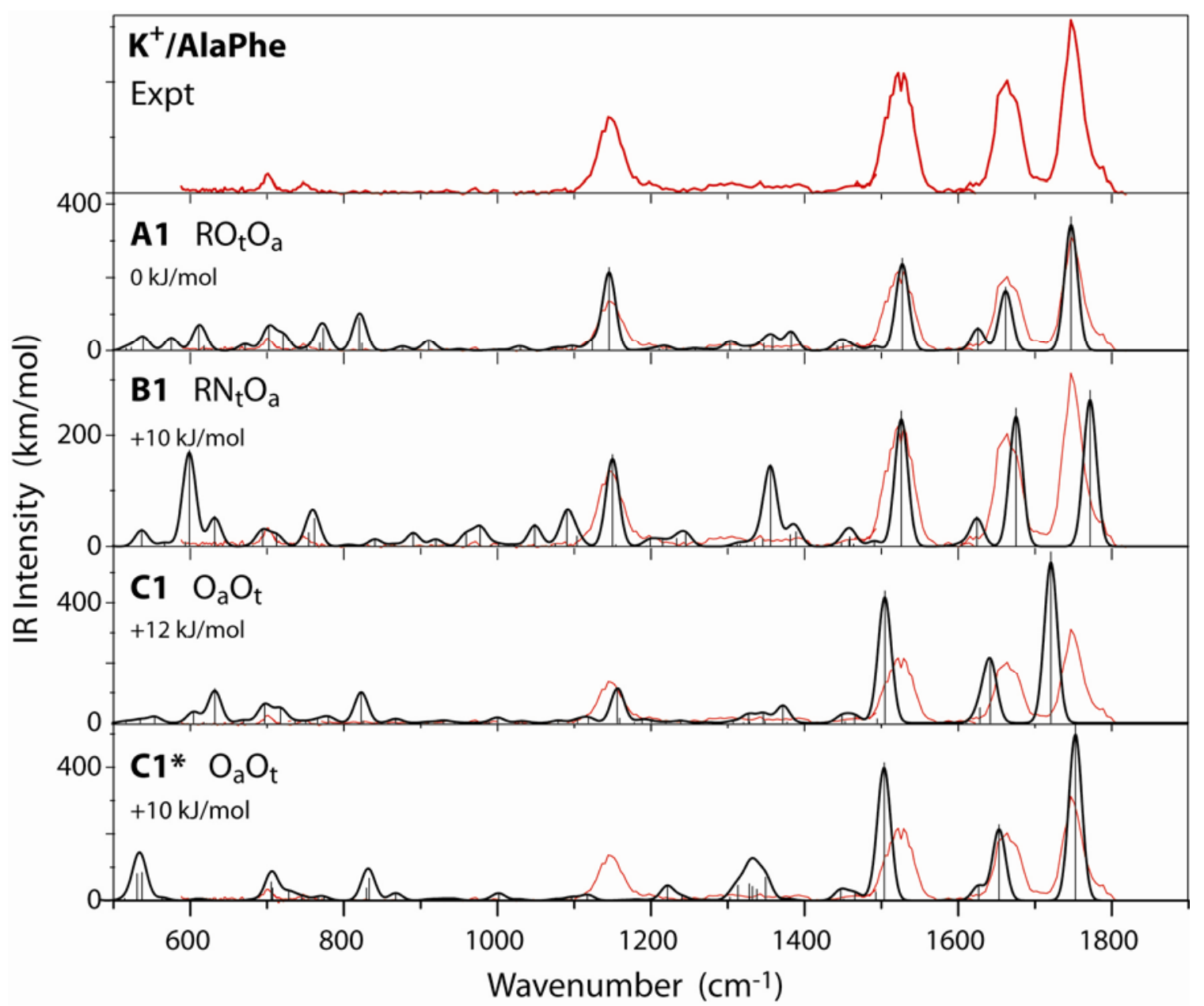

Fig. 8. Experimental spectrum (red) and low-energy conformations (black) of $\mathrm{K}^{+}$AlaPhe.

$\mathbf{M}^{+}$PheAla. The $\mathrm{Na}^{+}$and $\mathrm{K}^{+}$complexes of PheAla gave virtually indistinguishable spectra, suggesting similar conformations. Calculated spectra of chelation types A, B and $\mathrm{C}$ all have low enough free energies to be believable candidates, and all give not-too-bad fits to the spectra, so they all need to be carefully considered before drawing conclusions. In particular, the lowest four conformations found for $\mathrm{K}^{+} \mathrm{PheAla}$ have computationally identical free energies within reasonable uncertainty. $\mathrm{For} \mathrm{Na}^{+} \mathrm{PheAla}$, the $\mathrm{A} 1$ conformation has a somewhat more significant calculated free-energy advantage over the other three low-energy conformations, but the differences are still small. 
The non-ring chelated structures (types C and D) are spectroscopically less satisfactory than the A and B types. Four examples of type C and two of type D are given in the figures. Most convincing as an argument against the $\mathrm{C}$ structures is the fact that calculations give little intensity at $1130 \mathrm{~cm}^{-1}$, which is the location of the observed maximum of the broad experimental feature in this region. The predicted position of the $\mathrm{OH}$ bending peak in the $\mathrm{C}$ structures is around $1180 \mathrm{~cm}^{-1}$, which is not very close to the peak of the observed feature. Adding weight to this argument is the fact that the calculations of all four $\mathrm{C}$ spectra give the carboxyl $\mathrm{CO}$ peak about $30 \mathrm{~cm}^{-1}$ to the red of the observed peaks. The two conformations with structure $\mathrm{C} 2$ are further disfavored in that a strong peak is predicted, but not observed, for the $\mathrm{NH}_{2}$ scissoring vibration at 1600 $\mathrm{cm}^{-1}$. However, this last argument does not rule out the C chelation type in general, because the $\mathrm{NH}_{2}$ scissors is calculated to be very weak for the $\mathrm{C} 1$ structures. Further weighing against $\mathrm{C} 1$ structures is the fact that the peaks near 1500 and $1670 \mathrm{~cm}^{-1}$ are calculated at noticeably lower frequencies than observed. Finally, examples are shown (D1 in Figs. S5 and S6) of non-ring-chelated conformations with threefold chelation. These do not give a very good match to the observed spectra, particularly with respect to the predicted peak at $1600 \mathrm{~cm}^{-1}$, and this, along with the fact that no such conformations were found with free energies competitive with the ring-chelated conformations, makes the $\mathrm{D}$ chelation type unattractive. In summary, then, the non-ring-chelated geometries give quite poor agreement with the observed spectra. The C2 and D1 structures are probably not important, based on both energetic and spectroscopic arguments, and the $\mathrm{C} 1$ structure, while energetically feasible, is far enough from a good spectroscopic fit to make it unlikely as a major contributor, although some contribution from $\mathrm{C} 1$ cannot be ruled out. 
The ring-chelated conformations of type B1 shown in Figs. 5 and 6 (ring, amide oxygen and terminal $\mathrm{NH}_{2}$ ) are stronger contenders. Energetically, they are not far from chelation type A, and spectroscopically they are quite good. The calculated carboxyl CO stretch near 1750 is calculated slightly to the blue compared with type A chelation. It is possible, in the spectra of both metal-ion complexes, to match this predicted peak with a possible shoulder near 1780 for both metals, which would be consistent with a mixture of A1 and B1 conformations. The B1 calculations actually give a better fit than type A to the broad feature around $1150 \mathrm{~cm}^{-1}$. (The good fit to this feature is due to a strong mode at $1120 \mathrm{~cm}^{-1}$ of largely $\mathrm{H}$-bending character in the B1 structures that has no counterpart in the A structures.) Arguing against a predominance of the B structure type is the prediction for these structures of a strong $\mathrm{H}$-bending mode at $1350 \mathrm{~cm}^{-1}$ which is not observed in the spectra. In other respects, the B1 structure fits the spectra about as well as the A1 structures. We thus consider it quite possible that the B1 structures contribute importantly to the ion populations, which could even be a nearly equal mixture of A1 and B1 conformations. The "best match" simulated spectrum in Fig. 2 for $\mathrm{K}^{+}$PheAla is an equal mixture of structures A1, A2 and B1, and gives a satisfactory fit, although other combinations of the low-energy conformations are just about as good. Similarly, the "best match" in Fig. 2 for $\mathrm{Na}^{+}$PheAla is an equal mixture of $\mathrm{A} 1$ and $\mathrm{B} 1$, although other combinations are also reasonable.

$\mathbf{M}^{+}$AlaPhe. The A1 conformation has a significant free energy advantage for the AlaPhe complexes, although the B1 conformation is also energetically feasible for both metals, and non-ring-chelated $\mathrm{Cl}$ conformation are also not too unfavorable. The most stable calculated A1 conformations agree well with the $\mathrm{K}^{+} \mathrm{AlaPhe}$ spectrum, and not quite as well with the $\mathrm{Na}^{+} \mathrm{AlaPhe}$ spectrum. 
For $\mathrm{Na}^{+} \mathrm{AlaPhe}$, the $\mathrm{B} 1$ conformation also gives an acceptable match, and a combination of $\mathrm{A} 1$ and $\mathrm{B} 1$ gives a nice correspondence with the apparent splitting of the $\mathrm{C}=\mathrm{O}$ stretching feature around 1750 in the experimental spectrum. Thus the "best match" in Fig. 2 is suggested as an equal mixture of A1 and B1.

For $\mathrm{K}^{+}$AlaPhe no calculated conformation other than A1 agrees with all of the observed peaks, and it is concluded from the spectrum that A1 is the only important chelation mode. The B1, C1 and $\mathrm{C} 1$ * conformations all have fairly good stability, but none of them gives a very good fit to the spectrum. The D1 conformation shows somewhat better agreement with the spectrum, but at $+23 \mathrm{~kJ} / \mathrm{mol}$ relative free energy, it is probably not sufficently stable to be a serious possibility. Thus the "best match" for this spectrum in Fig. 2 is assigned as pure A1.

Other Chelation Possibilities. Fourfold chelated conformations of the complexes were found as minima on the potential energy surfaces, but none were found having stability competitive with the various low-energy two-fold or three-fold chelation patterns discussed above. A typical example of such a conformation for $\mathrm{Na}^{+} \mathrm{PheAla}$ is $\mathrm{NaFA}$ E1 $\mathrm{RO}_{\mathrm{t}} \mathrm{O}_{\mathrm{a}} \mathrm{N}_{\mathrm{t}}$, whose structure and calculated spectrum are shown in Figs. S1 and S5, respectively. Its calculated spectrum is actually not bad (except for a too-intense predicted $\mathrm{NH}_{2}$ peak at $1590 \mathrm{~cm}^{-1}$ ), but it is calculated to be disfavored by $22 \mathrm{~kJ} / \mathrm{mol}$ in free energy.

Comparisons. The dipeptide spectra allow us to view the spectroscopic evolution from amino acid complexes to peptides, as shown in Fig. 9. The spectrum of $\mathrm{K}^{+} \mathrm{Phe}$ was reported previously, ${ }^{[16]}$ but its quality was poor, and the improved ion cooling in the current configuration of the instrument ${ }^{[7]}$ allowed us to obtain the new, much better 
spectrum displayed in the figure. Also shown in the figure is the spectrum reported for the +12 charge state of potassiated protonated bovine cytochrome $\mathrm{C}$.

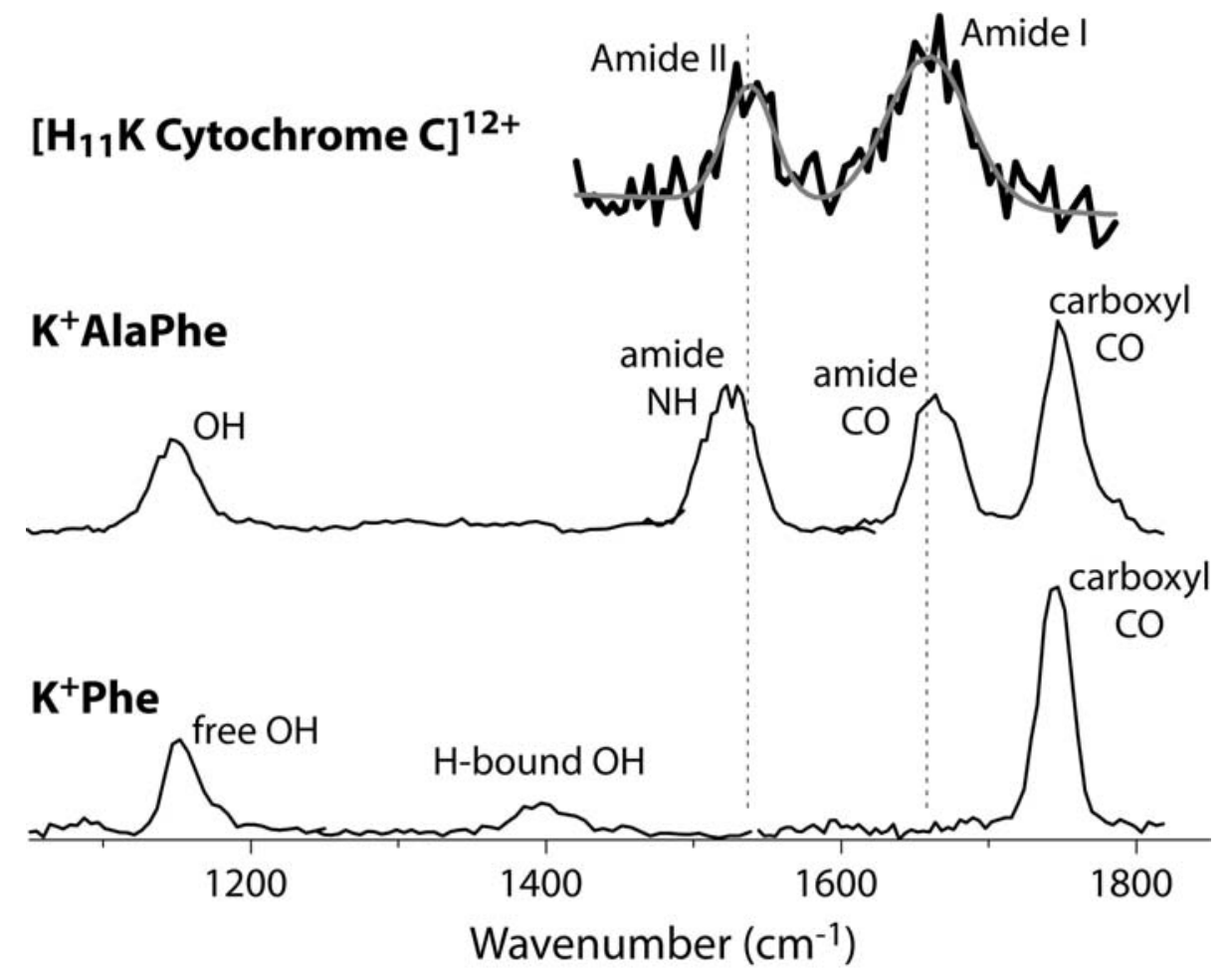

Fig. 9. Comparison of the IRMPD spectra of the $\mathrm{K}^{+}$complexes of Phe and AlaPhe, and the $12^{+}$protonated charge state of cytochrome-C.

Comparing the $\mathrm{K}^{+} \mathrm{Phe}$ and $\mathrm{K}^{+} \mathrm{PheAla}$ spectra, we see the appearance of the characteristic amide bands in the dipeptide spectrum. Amide I $(\mathrm{C}=\mathrm{O}$ stretch $)$ and Amide II (N-H bend) are in blank regions of the $\mathrm{K}^{+}$Phe spectrum. Both spectra show the strong peak for the terminal carboxyl $\mathrm{CO}$ group, and a strong peak for the carboxyl $\mathrm{OH}$ group not $\mathrm{H}$-bound to the $\mathrm{NH}_{2}$ group. The $\mathrm{K}^{+}$Phe spectrum also shows a peak at $1400 \mathrm{~cm}^{-1}$ corresponding to conformations where the $\mathrm{OH}$ group is hydrogen-bonded to the $\mathrm{NH}_{2}$ group. No such peak is predicted for the dipeptide, since it is found to be sterically 
impractical to form low-energy conformations having such a hydrogen bond in this case. In both monomer and dipeptide cases a peak is predicted near $1600 \mathrm{~cm}^{-1}$ for the $\mathrm{NH}_{2}$ scissors vibration, but its predicted intensity is low; it is barely discernible in the monomer case, and not seen at all in the dipeptide case.

The cytochrome $\mathrm{C}$ spectrum was acquired only over a more limited wavelength region, but it clearly shows the Amide I and Amide II bands. In the protein the position of the Amide I band is redshifted relative to the dipeptide, whereas the Amide II band is blueshifted, as would be expected for increased hydrogen bonding interactions. Interestingly, the peak widths of both bands are comparable in both the dipeptide and protein. In the spectrum of the protein no peak is visible for the carboxylic acid $\mathrm{CO}$ stretching vibration. The disappearance of this peak is expected, since there is only a single terminal carboxylic acid, whereas there are over a hundred amide CO groups (103, to be exact). So even if this carboxylic acid is not deprotonated, as it may be in the protein, its characteristic peak will be insignificant relative to the strong amide peaks. Thus the dipeptide spectrum represents a graphic transition from the monomer complex to the protein, showing recognizable bands corresponding both to the terminal carboxyl group that plays a prominent role in the monomer complex spectrum, and also to the amide linkage that dominates the spectroscopy of large peptides.

Comparison of DFT Functionals. There was a significant difference in the treatment of ring chelation by the B3LYP functional versus the MPW1PW91 functional. 38 dipeptide complex conformations were calculated with both functionals. Over this sample, MPW1PW91 was found to favor ring-bound conformations more strongly than B3LYP by $3 \mathrm{~kJ} / \mathrm{mol}$. 
It is not known a priori which functional is more accurate in treating the cation- $\pi$ interaction. The present results give some experimental evidence on this question. There is one case where the functionals make opposite predictions about the ground state, which is $\mathrm{K}^{+}$PheAla, where a non-ring-bound structure $\left(\mathrm{C} 1, \mathrm{O}_{\mathrm{t}} \mathrm{O}_{\mathrm{a}}\right)$ was calculated by B3LYP to be the most stable structure by several $\mathrm{kJ} / \mathrm{mol}$, while MPW1PW91 gives two ringchelated structures with greater stability than this one. The spectroscopic result is in favor of the MPW1PW91 predictions, in that both of the structures predicted to be most stable are excellent fits to the observed spectrum, while the $\left(\mathrm{Cl}, \mathrm{O}_{\mathrm{t}} \mathrm{O}_{\mathrm{a}}\right)$ structure is a poor fit. This is another piece of evidence to add to previous indications ${ }^{[2,30]}$ that MPW1PW91 is superior in its thermochemical treatment of ring-chelated complexes. Accordingly, we adopt MPW1PW91 values for the thermochemical comparisons here. However, we have retained the B3LYP results for vibrational properties and spectral predictions, to provide more direct comparison with other laboratories' computations, and because there is no indication of superiority of MPW1PW91 for vibrational properties. ${ }^{[4]}$

\section{Conclusions}

The combination of computational results and spectroscopic observations gives a number of structural conclusions about these dipeptide complexes. Firm conclusions are that there are no zwitterionic conformations in the populations, and that the terminal $\mathrm{OH}$ group of the C-terminus is exclusively in the endo conformation. Among the five available Lewis-basic chelation sites, it is clear that the amide $\mathrm{CO}$ group always chelates the metal ion, and the terminal $\mathrm{OH}$ group does not do so. This is also consistent with previous computational results on the potassiated pentapeptides Leu-enkepahlin and 
bradykinin, where the peptides were found to be wrapped around the metal cation, maximizing the electrostatic interactions with the carbonyl oxygens. ${ }^{[16]}$

Among the remaining three possible sites, there are possibilities for various chelation combinations. The spectroscopic evidence indicates that the ring always provides one chelation site in a cation- $\pi$ binding mode. For the $\mathrm{Na}^{+}$complexes the metalion/ring interaction is strong enough so that non-ring-chelated conformations were found to be energetically uncompetitive, reinforcing the spectroscopic evidence. For the $\mathrm{K}^{+}$ complexes, non-ring-chelated complexes were located having more nearly competitive energies, but it was considered that the spectroscopic arguments in favor of ring chelation were strong in all cases. It is notable that thermochemical calculations with the MPW1PW91 functional were in better accord with the relatively high favorability of the ring binding site than the B3LYP functional, and the latter functional was considered to be less satisfactory than the former for modeling this aspect of metal-ion binding for sodium and potassium ions.

Having established the amide $\mathrm{CO}$ and the ring as two chelation sites, we found that there is definitely a third metal chelation at one of the terminal sites, either the terminal $\mathrm{CO}$ group, or the terminal $\mathrm{NH}_{2}$ group. In general conformations with either of these chelation patterns were acceptable on both energetic and spectroscopic grounds, and it seemed likely that the populations were mixtures of the two types. Only for $\mathrm{K}^{+}$AlaPhe was there a clear preference for one of the possibilities, namely A-type chelation at the $\mathrm{O}_{\mathrm{t}}$ site.

The gas-phase spectroscopy of the dipeptide complexes was found to give a nice transition between the spectrum of the monomeric Trp complex and the cytochrome-C spectrum. The monomer complex is dominated by vibrations associated with the $\mathrm{N}$ - 
terminal and C-terminal groups, while the cytochrome-C spectrum is dominated by amide bands. The dipeptide complexes show vibrational features corresponding to both of these types of vibrational modes.

Acknowledgments. This work is financially supported by the "Nederlandse Organisatie voor Wetenschappelijk Onderzoek" (NWO) and grant \#CHE-9909502 from the National High Magnetic Field Laboratory (Tallahassee, FL). RCD acknowledges travel support from the National Science Foundation. The skillful assistance by the FELIX staff is gratefully acknowledged.

Supplementary materials available: Structures of computed complexes; additional computed spectra; complete Ref. 11. 


\section{References}

[1] C. Kapota, J. Lemaire, P. Maître, G. Ohanessian J. Am. Chem. Soc. 2004, 126, 18361842.

[2] T. Shoeib, K. W. M. Siu, A. C. Hopkinson J. Phys. Chem. A. 2002, 106, 6121-6128.

[3] T. Marino, N. Russo, M. Toscano J. Phys. Chem. B. 2003, 107, 2588-2594.

[4] R. A. Jockusch, W. D. Price, E. R. Williams J. Phys. Chem. A. 1999, 103, 9266.

[5] M. M. Kish, G. Ohanessian, C. Wesdemiotis Int. J. Mass Spectrom. 2003, 227, 509524.

[6] E. R. Talaty, B. A. Perera, A. L. Gallardo, J. M. Barr, M. J. Van Stipdonk J. Phys. Chem. A. 2001, 105, 8059.

[7] N. C. Polfer, J. Oomens, D. T. Moore, G. von Helden, G. Meijer, R. C. Dunbar J. Am. Chem. Soc. 2006, 128, 517-525.

[8] C. H. Ruan, M. T. Rodgers J. Am. Chem. Soc. 2004, 126, 14600-14610.

[9] M. F. Bush, J. T. O'Brien, J. S. Prell, R. J. Saykally, E. R. Williams J. Am. Chem. Soc. 2007, 129, 1612-1622.

[10] M. T. Rodgers, P. B. Armentrout Accts. Chem. Research. 2004, 37, 989-998.

[11] L. Operti, R. Rabezzana Mass Spectrom. Rev. 2003, 22, 407-428.

[12] O. P. Balaj, C. Kapota, J. Lemaire, P. Maître, G. Ohanessian, to be published. Private communication, G. Ohanessian.

[13] R. C. Dunbar J. Phys. Chem. A. 2000, 104, 8067-8074.

[14] V. Ryzhov, R. C. Dunbar, B. Cerda, C. Wesdemiotis J. Am. Chem. Soc. 2000, 11, 1037-1046. 
[15] A. Gapeev, R. C. Dunbar Journal of the American Chemical Society. 2001, 123, $8360-8365$.

[16] N. C. Polfer, B. Paizs, L. C. Snoek, I. Compagnon, S. Suhai, G. Meijer, G. Von Helden, J. Oomens J. Am. Chem. Soc. 2005, 127, 8571-8579.

[17] H. Oh, K. Breuker, S. K. Sze, B. K. Carpenter, F. W. McLafferty Proc. Nat. Acad. Sci. U.S.A. 2002, 99, 15863-15868.

[18] H. B. Oh, C. Lin, H. Y. Hwang, H. Zhai, K. Breuker, V. Zabrouskov, B. K. Carpenter, F. W. McLafferty J. Am. Chem. Soc. 2005, 127, 4076-4083.

[19] A. Kamariotis, O. V. Boyarkin, S. R. Mercier, R. D. Beck, M. F. Bush, E. R. Williams, T. R. Rizzo J. Am. Chem. Soc. 2006, 128, 905-916.

[20] J. Oomens, N. Polfer, D. T. Moore, L. van der Meer, A. G. Marshall, J. R. Eyler, G. Meijer, G. von Helden Phys. Chem. Chem. Phys. 2005, 7, 1345-1348.

[21] L. MacAleese, A. Simon, T. B. McMahon, J.-M. Ortega, D. Scuderi, J. Lemaire, P. Maître Int J. Mass Spectrom. 2006, 149-150, 14-20.

[22] F. M. Siu, N. L. Ma, C. W. Tsang Chemistry-a European Journal. 2004, 10, 19661976.

[23] J. M. Talley, B. A. Cerda, G. Ohanessian, C. Wesdemiotis Chem. Eur. J. 2002, 8, 1377-1388.

[24] B. Lucas, G. Gregoire, J. Lemaire, P. Maître, J.-M. Ortega, A. Rupenyan, B. Reimann, J. P. Schermann, C. Desfrançois Phys. Chem. Chem. Phys. 2004, 6, 26592663.

[25] N. C. Polfer, J. Oomens, R. C. Dunbar Phys. Chem. Chem. Phys. 2006, 8, 27442751. 
[26] D. Oepts, A. F. G. van der Meer, P. W. Amersfoort Infrared Phys. Technol. 1995, $36,297$.

[27] J. Valle, J. R. Eyler, J. Oomens, D. T. Moore, A. F. G. van der Meer, G. von Helden, G. Meijer, C. L. Hendrickson, A. G. Marshall, G. T. Blakney Rev. Sci. Instrum. 2005, $76,023103$.

[28] J. Oomens, A. G. G. M. Tielens, B. Sartakov, G. von Helden, G. Meijer Astrophys. J. 2003, 591, 968-985.

[29] R. C. Dunbar Journal of Physical Chemistry A. 2002, 106, 7328-7337.

[30] J. Oomens, D. T. Moore, G. von Helden, G. Meijer, R. C. Dunbar J. Am. Chem. Soc. 2004, 126, 724-725.

[31] Gaussian03W, M. J. Frisch et al., Gaussian 03W, Version 6.0, Gaussian, Inc., Pittsburgh PA, 2003.

[32] NIST Mass Spec Data Center, S.E. Stein, director, "Infrared Spectra" in NIST Chemistry WebBook, NIST Standard Reference Database Number 69, Eds. P.J. Linstrom and W.G. Mallard, March 2003, National Institute of Standards and Technology, Gaithersburg MD, 20899 (http://webbook.nist.gov).

[33] P. B. Armentrout, M. T. Rodgers J. Phys. Chem. A. 2000, 104, 2238-2247.

[34] P. Wang, C. Wesdemiotis, C. Kapota, G. Ohanessian J. Am Soc. Mass Spectrom. 2007, 18, 541-552.

[35] B. A. Cerda, S. Hoyau, G. Ohanessian, C. Wesdemiotis Journal of the American Chemical Society. 1998, 120, 2437-2448.

[36] M. Kish, C. Wesdemiotis, G. Ohanessian J. Phys. Chem. B. 2004, 108, 3086-3091. 
[37] C. Kapota, G. Ohanessian Phys. Chem. Chem. Phys. 2005, 7, 3744-3755.

[38] C. H. S. Wong, N. L. Ma, C. W. Tsang Chemistry-a European Journal. 2002, 8, 4909-4918.

[39] M. Benzakour, M. McHarfi, A. Cartier, A. Daoudi Journal of Molecular StructureTheochem. 2004, 710, 169-174.

[40] S. Abirami, C. H. S. Wong, C. W. Tsang, N. L. Ma, N. K. Goh Journal of Molecular Structure-Theochem. 2005, 729, 193-202.

[41] B. B. Koleva, T. Kolev, S. Y. Zareva, M. Spiteller J. of Mol. Struct. 2007, 831, 165173.

[42] R. M. Moision, P. B. Armentrout J. Phys. Chem. A. 2002, 106, 10350-10362.

[43] R. M. Moision, P. B. Armentrout Phys. Chem. Chem. Phys. 2004, 6, 2588-2599.

[44] T. Steiner, G. Koellner J. Mol. Biol. 2001, 305, 535-557.

[45] D. T. Moore, J. Oomens, J. R. Eyler, G. von Helden, G. Meijer, R. C. Dunbar J. Am. Chem. Soc. 2005, 127, 7243-7254. 


\section{Supplementary Material.}

Structures of all the complexes listed in Table 2.
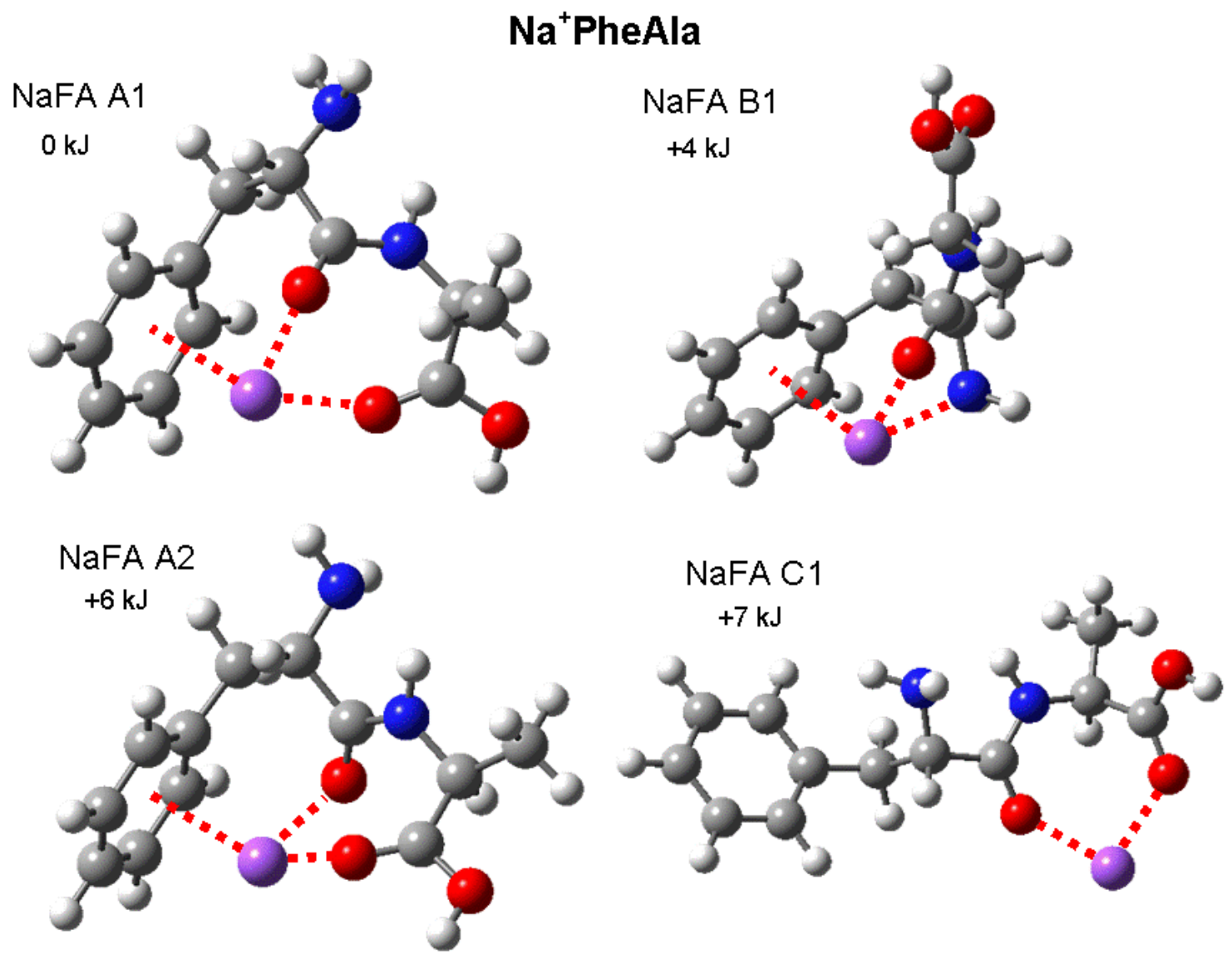

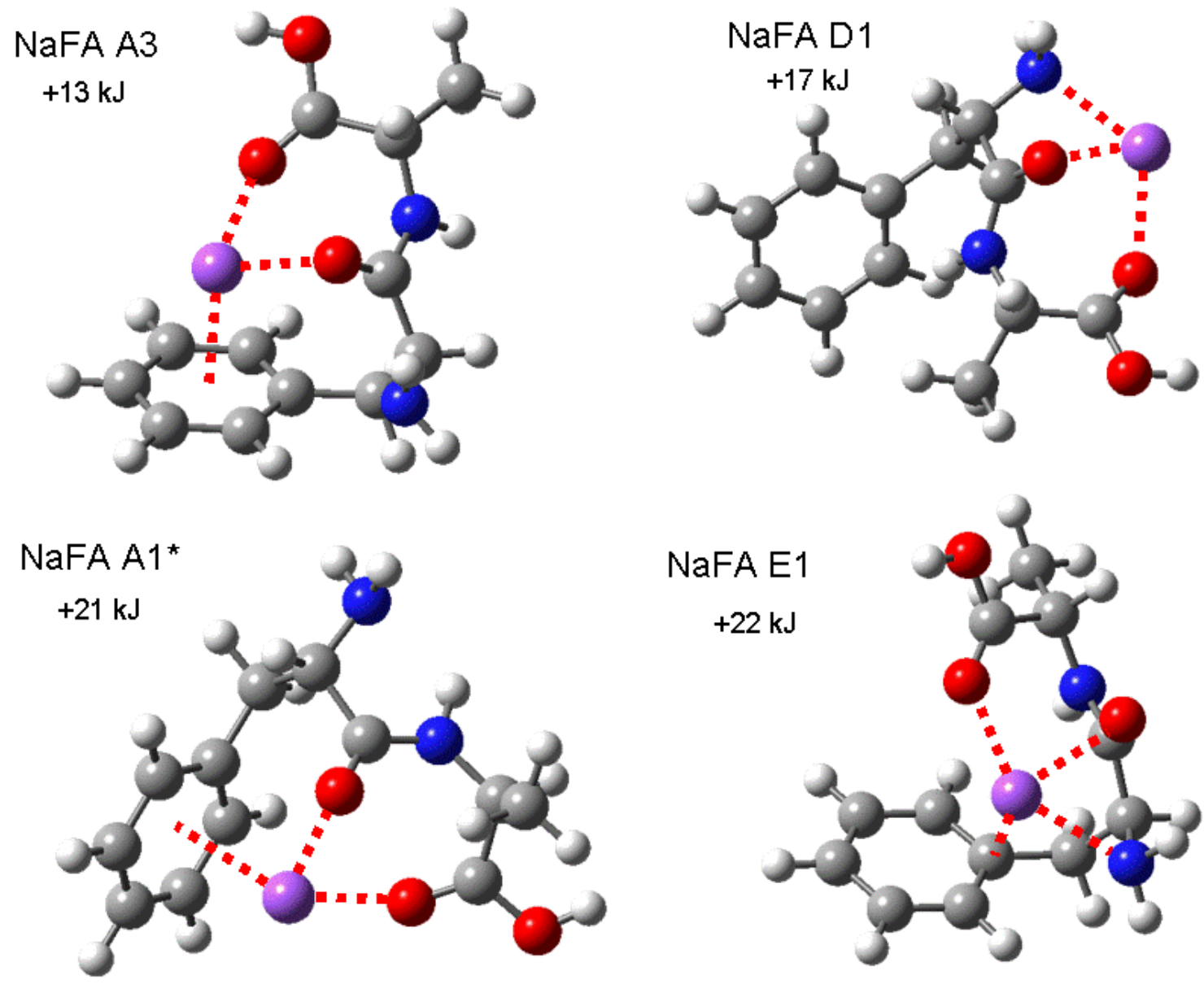

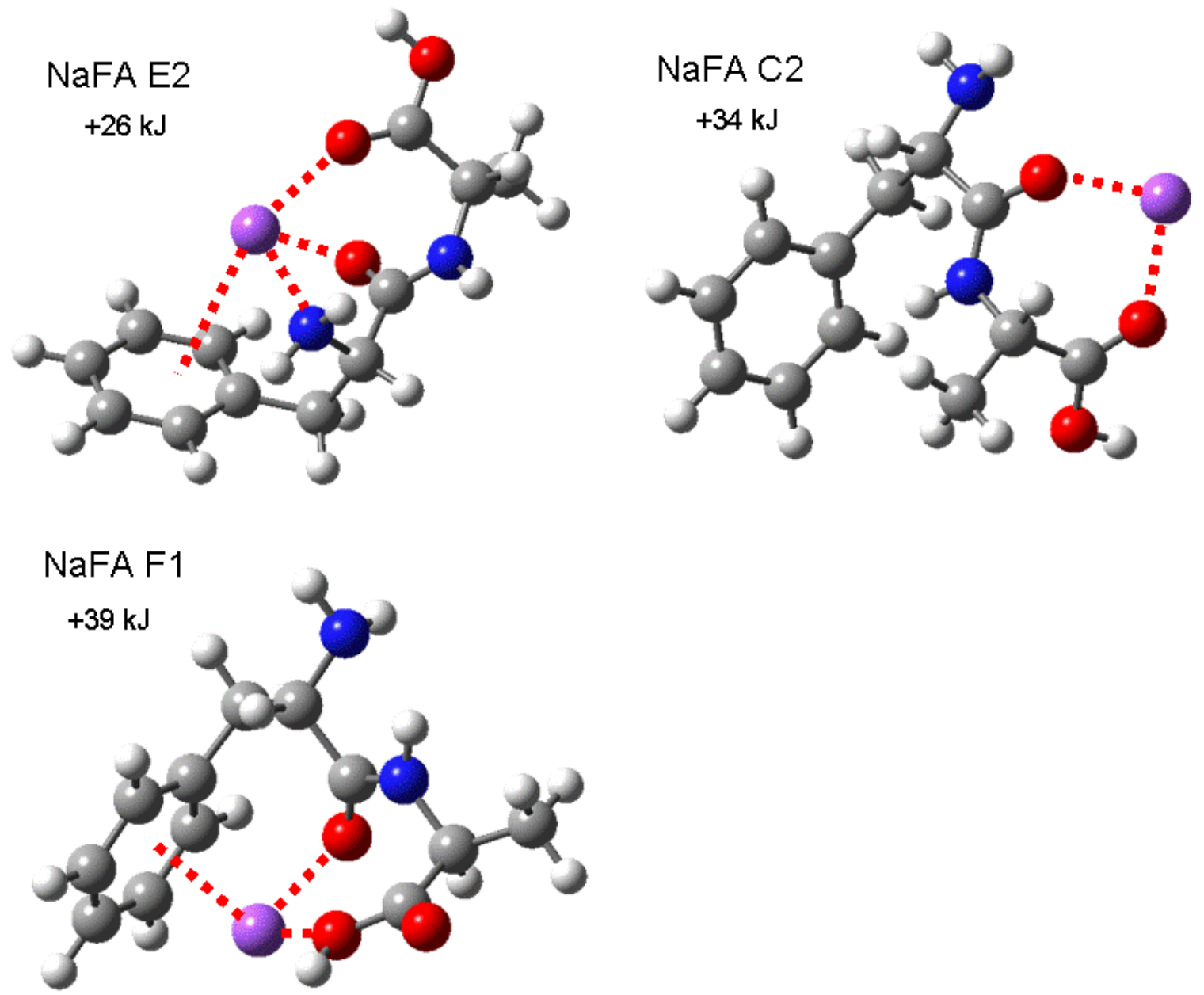

Fig. S1. Structures of $\mathrm{Na}^{+} \mathrm{PheAla}$ 


\section{$K^{+}$PheAla}
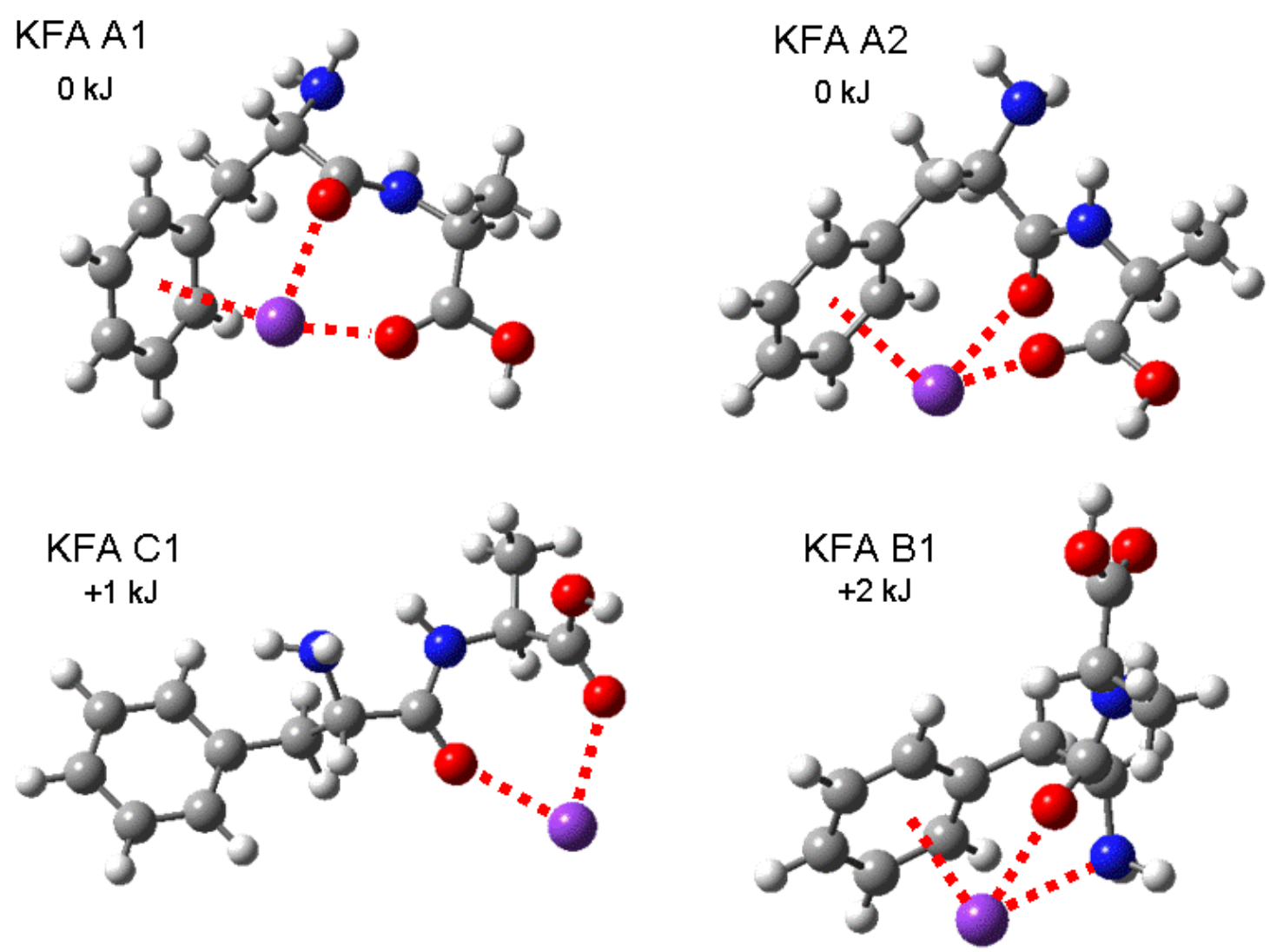

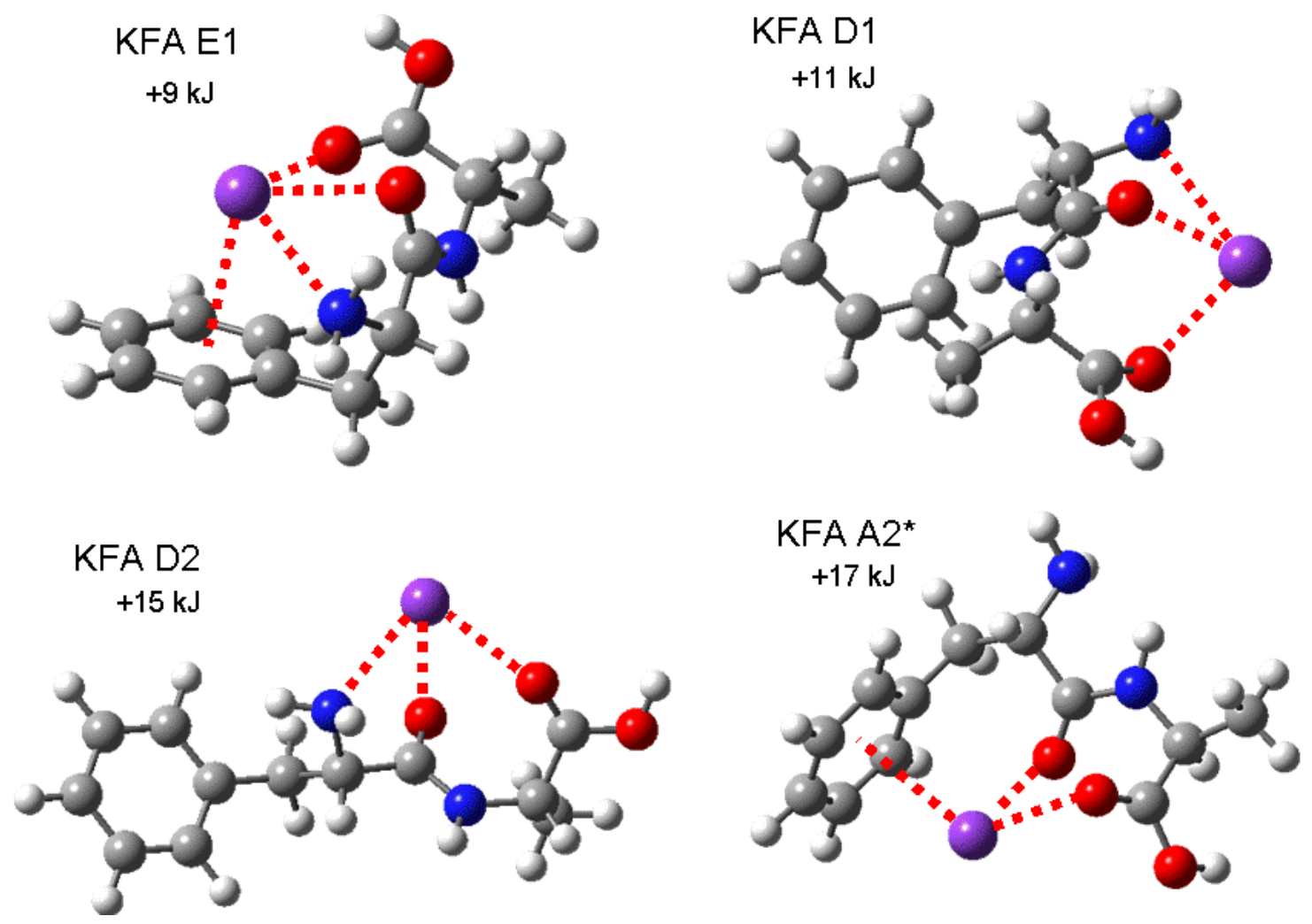

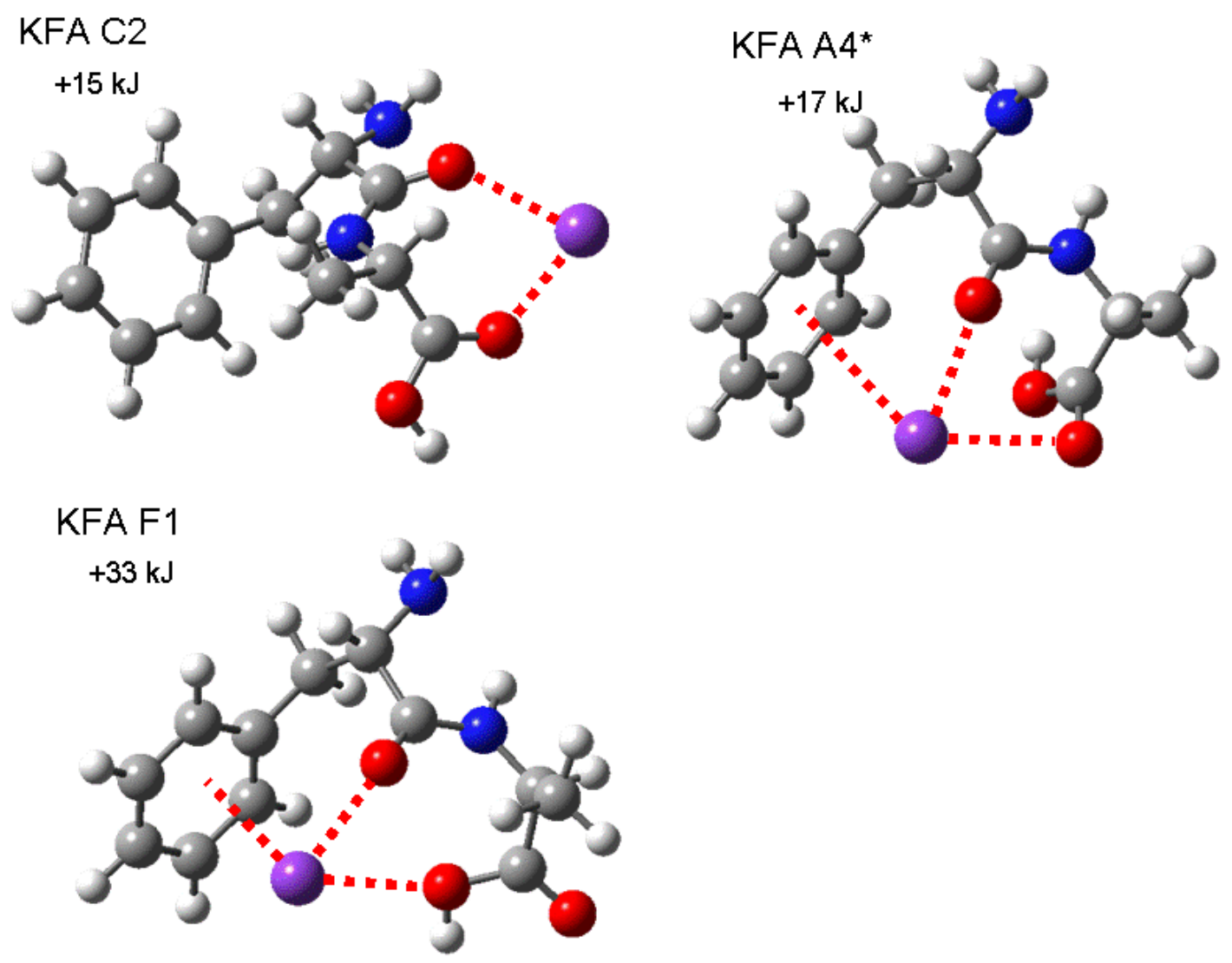

Fig. S2. Structures of $\mathrm{K}^{+}$PheAla 

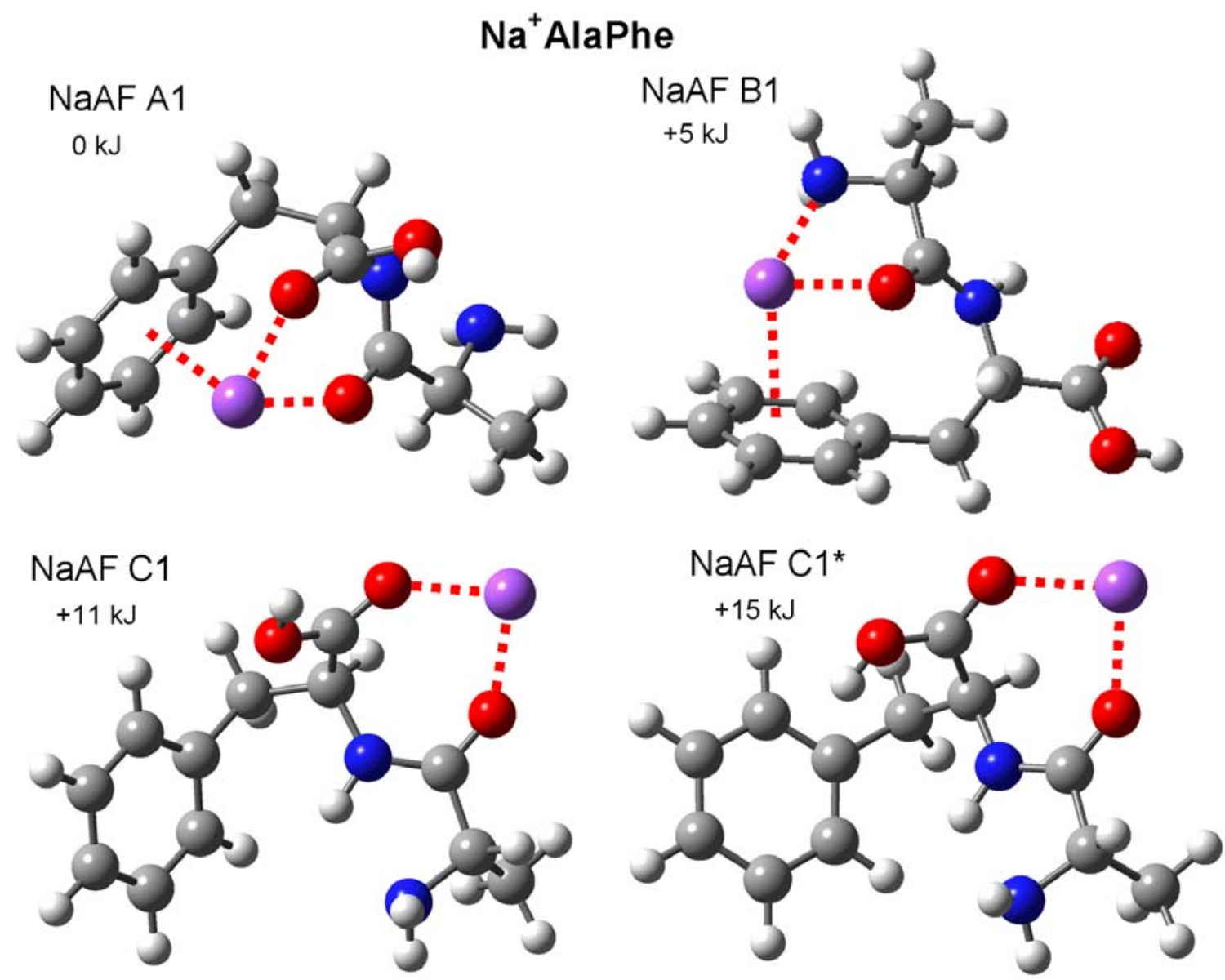

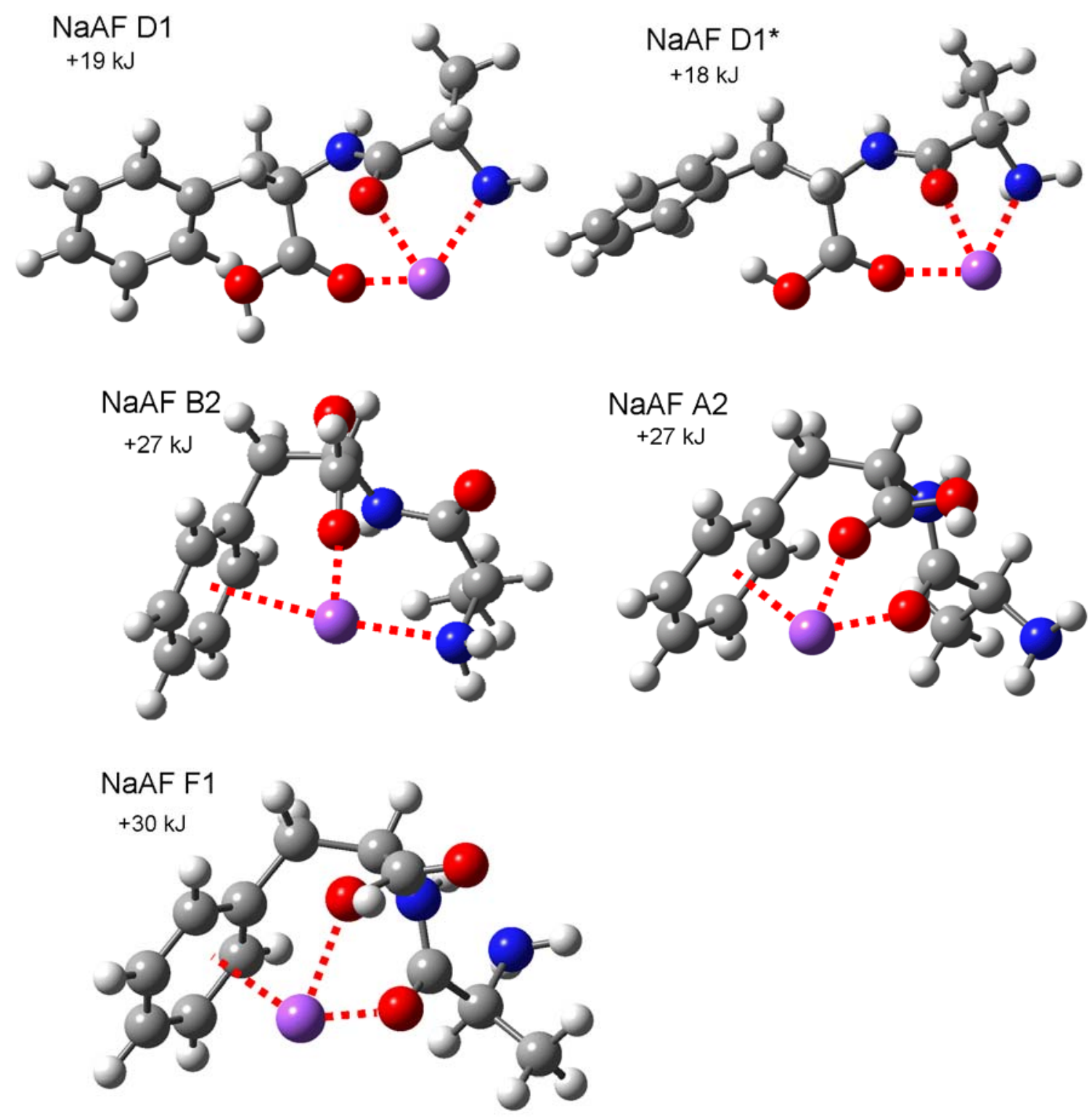

Fig. S3. Structures of $\mathrm{Na}^{+}$AlaPhe complexes. 

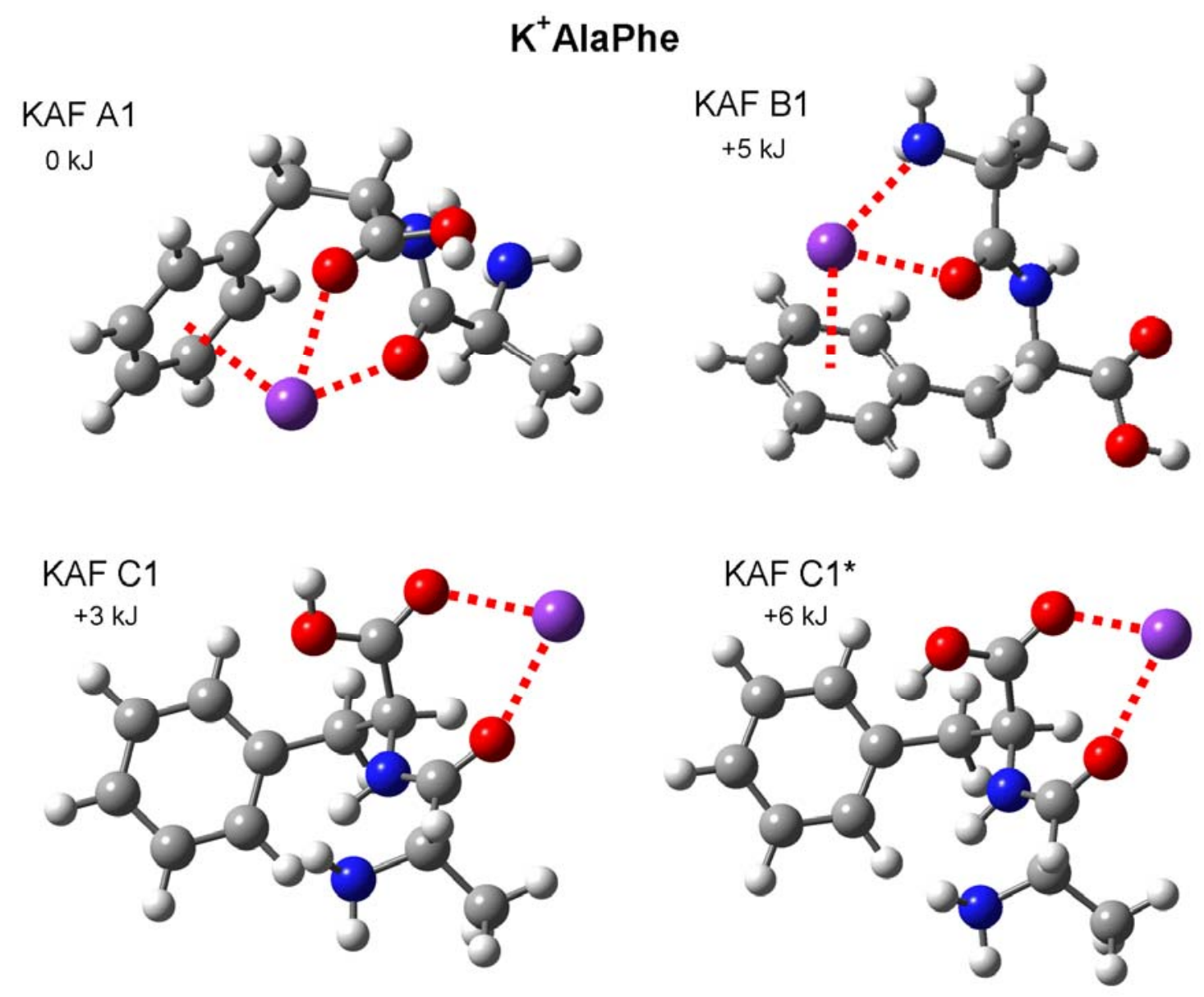

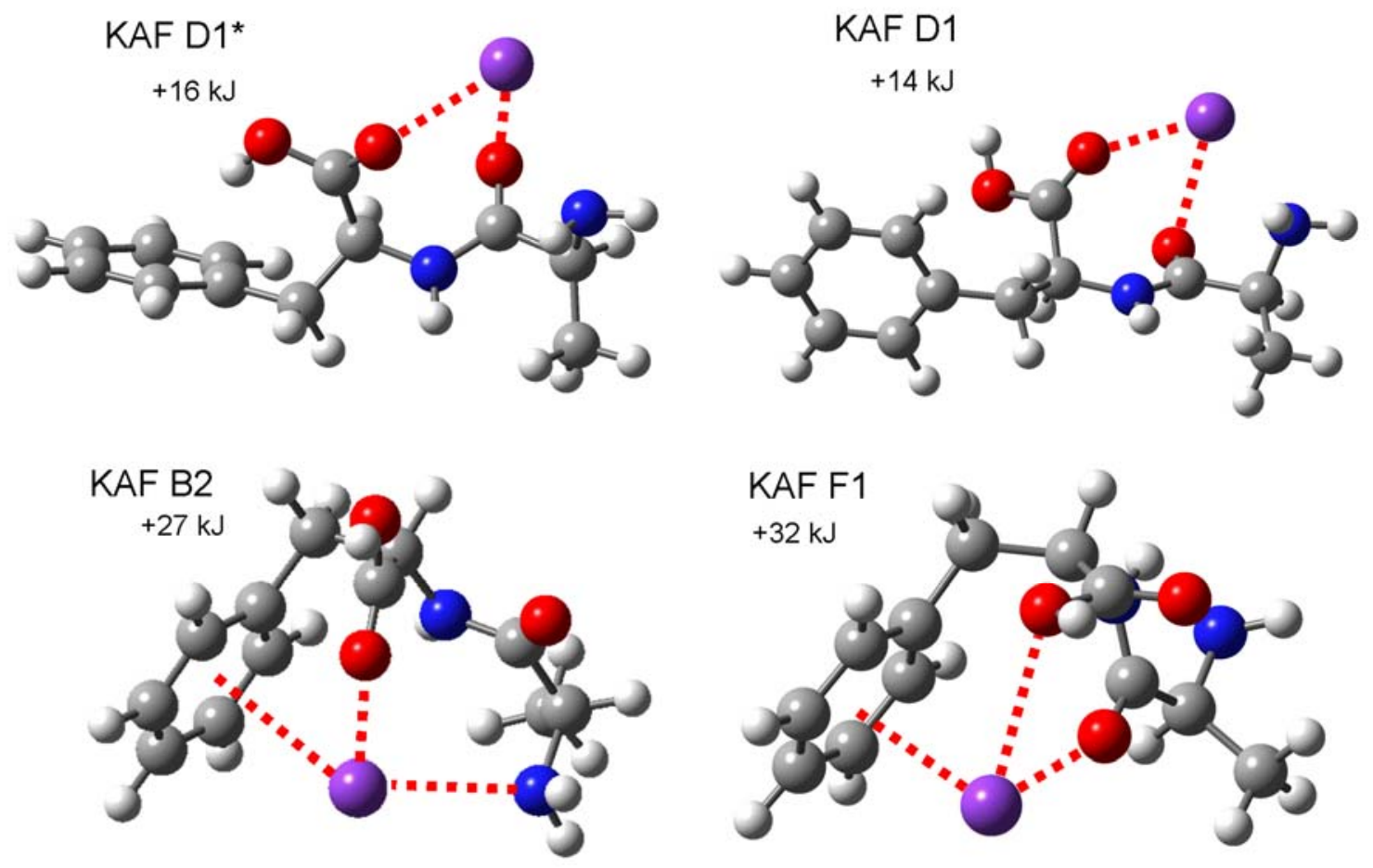

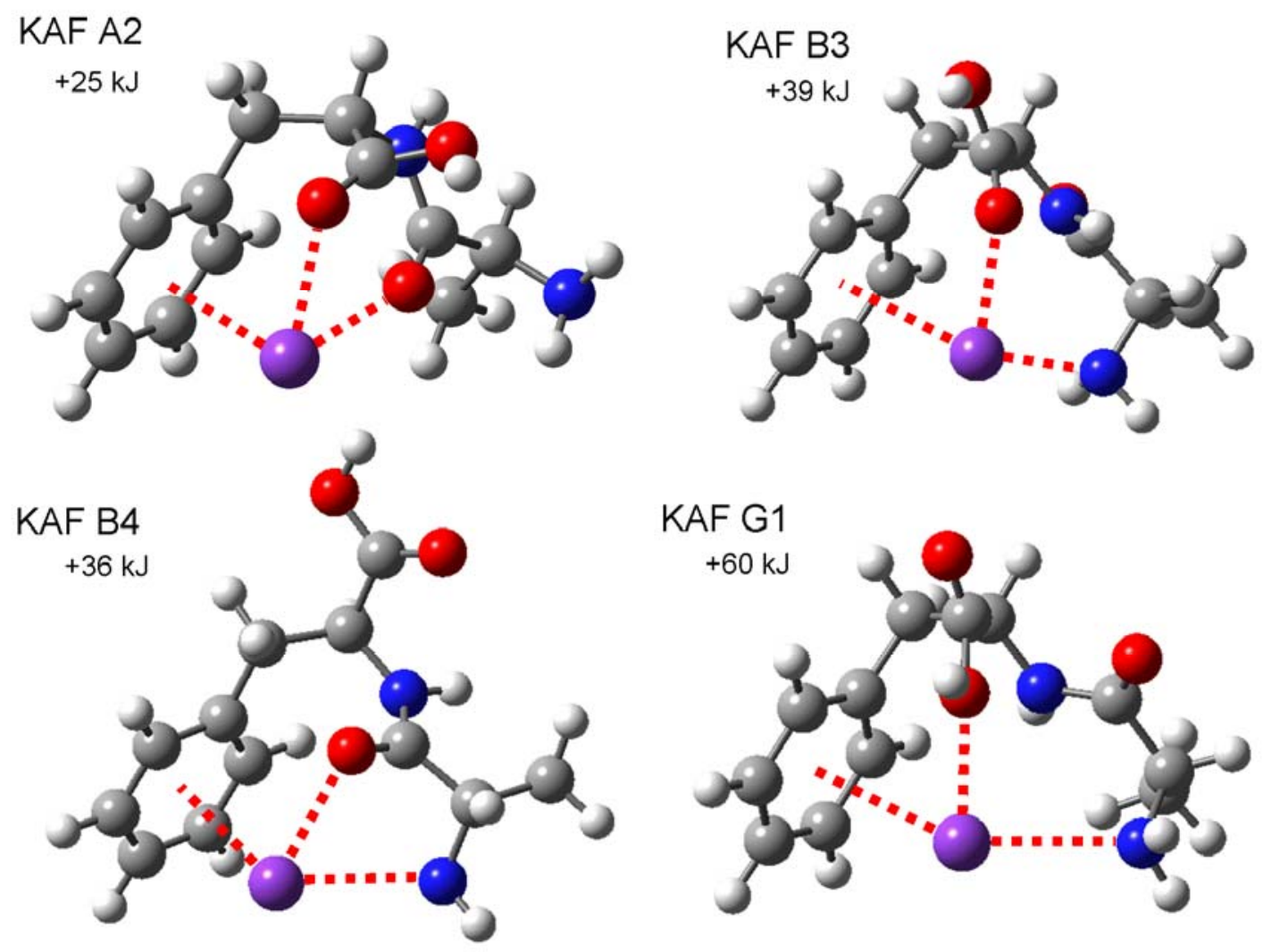

Fig. S4. Structures of $\mathrm{K}^{+} \mathrm{AlaPhe}$ complexes. 


\section{Additional Computed Spectra}

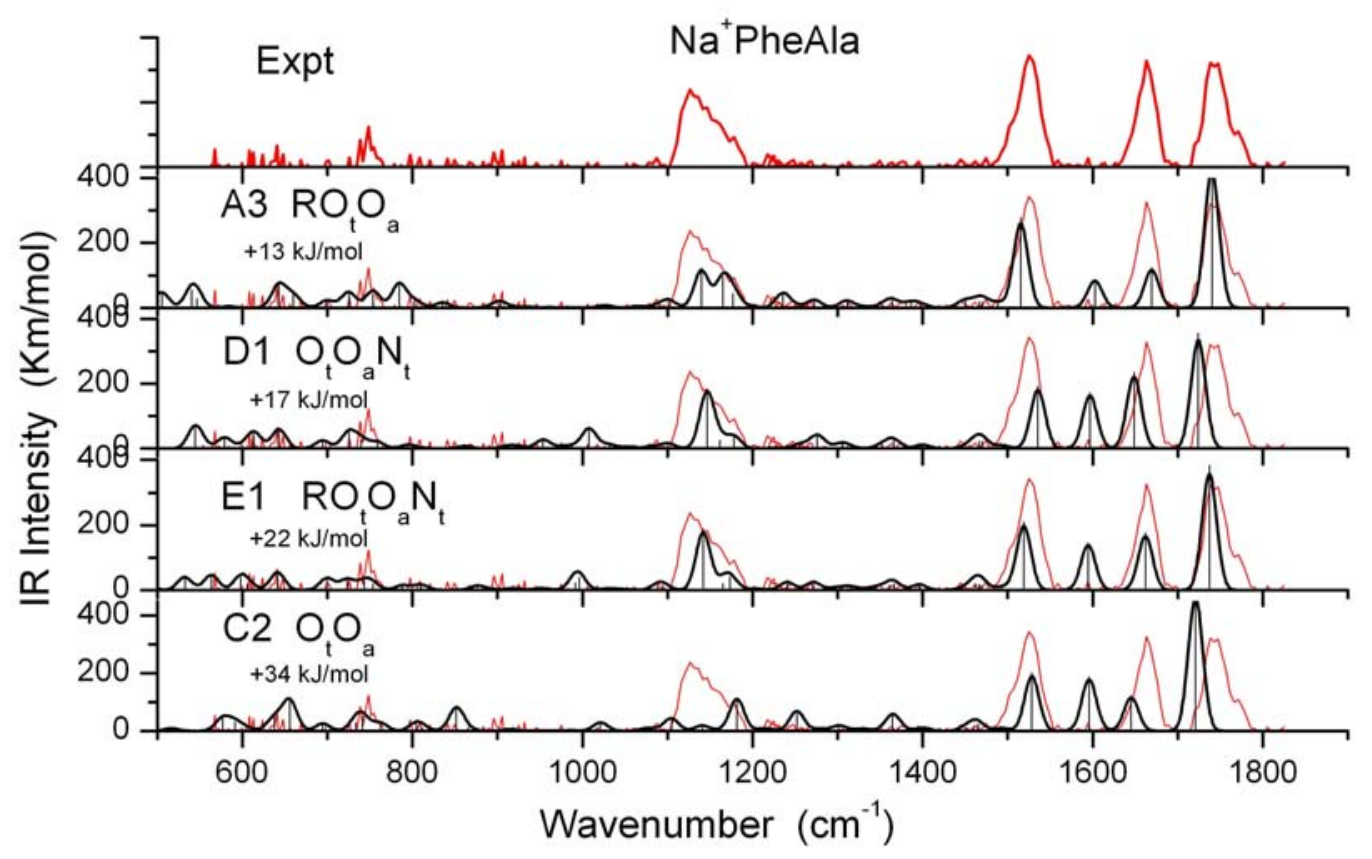

Fig. S5. Experimental spectrum (red) and various computed conformations (black) of $\mathrm{Na}^{+}$PheAla. 


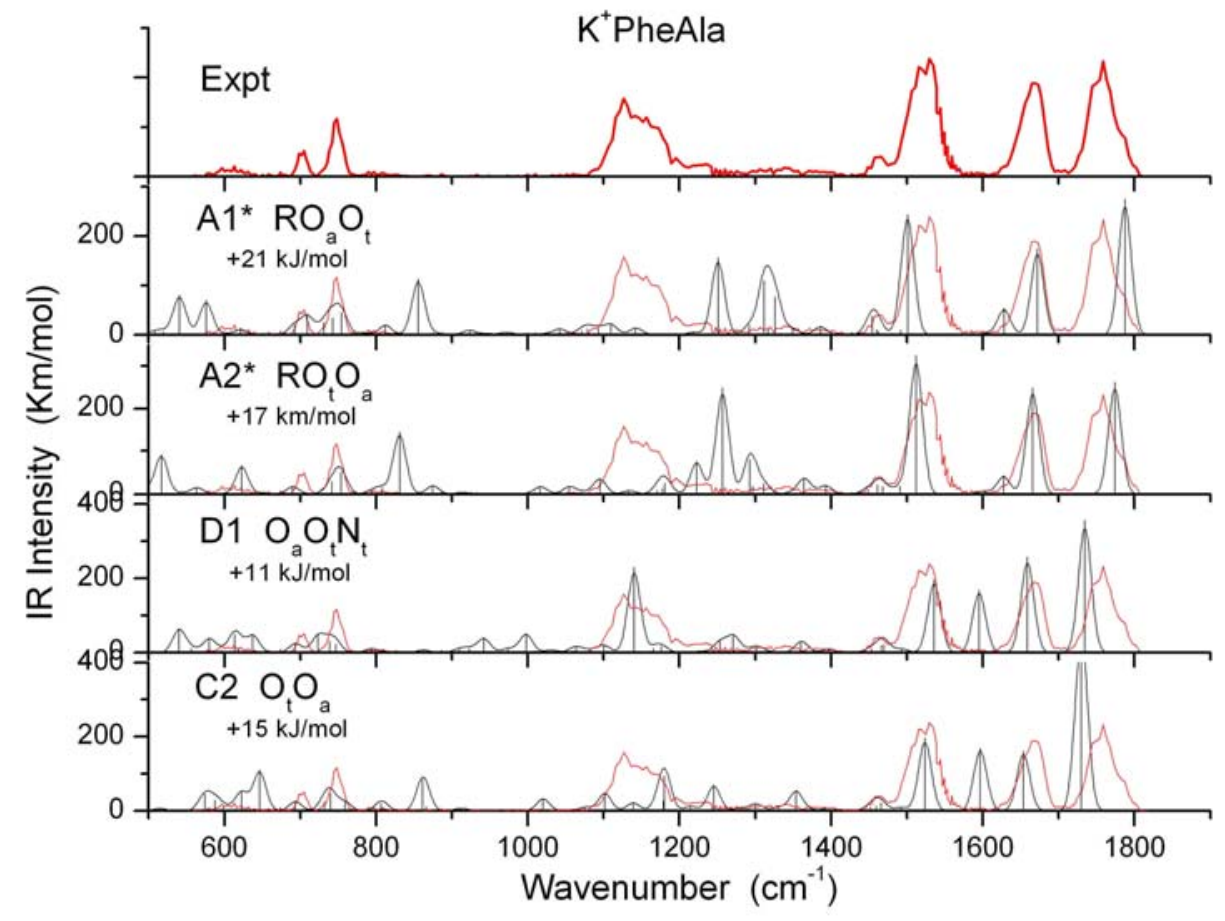

Fig. S6. Experimental spectrum (red) and various computed conformations (black) of $\mathrm{K}^{+}$PheAla. 


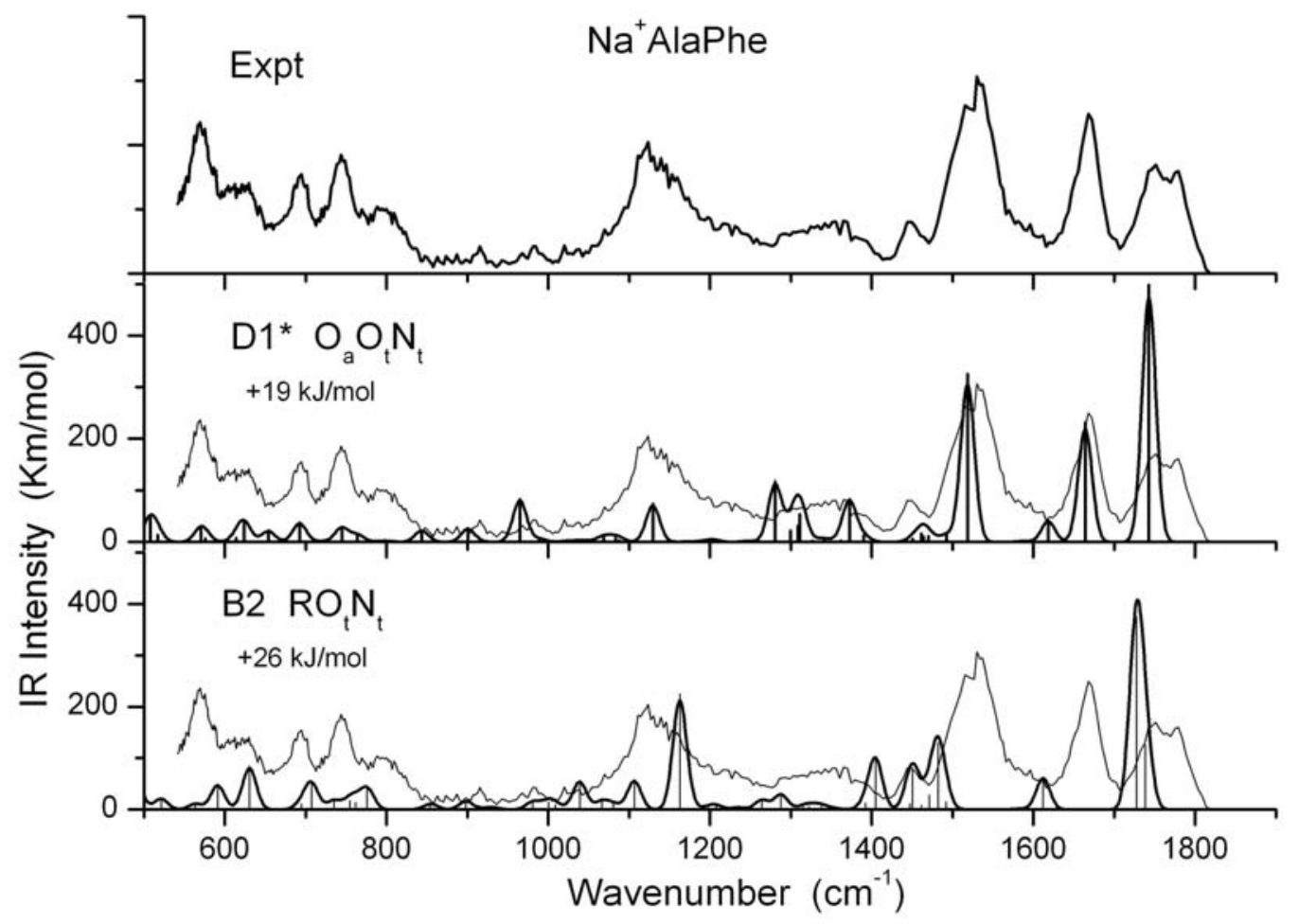

Fig. S7. Experimental spectrum (red) and various computed conformations (black) of $\mathrm{Na}^{+}$AlaPhe. 


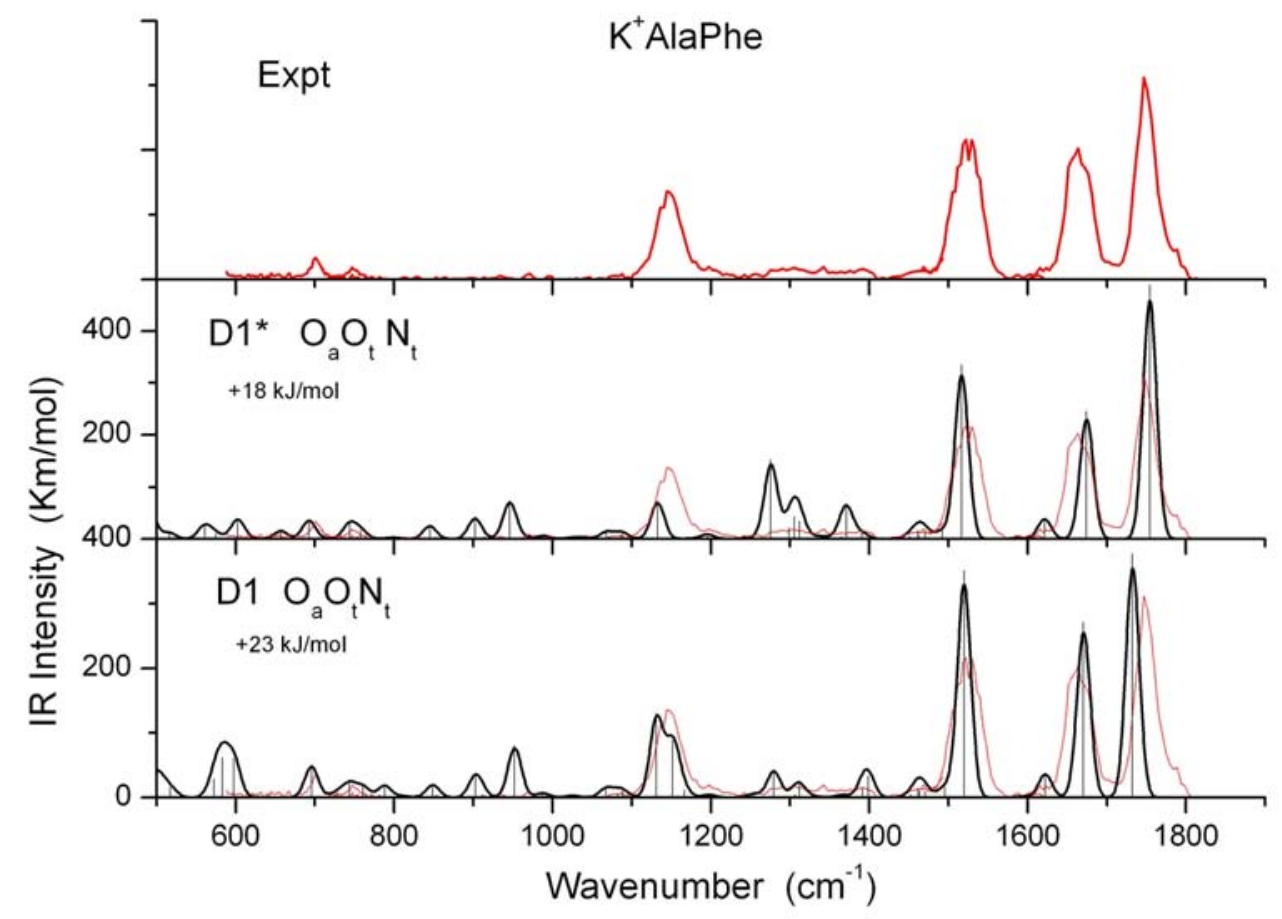

Fig. S8. Experimental spectrum (red) and various computed conformations (black) of $\mathrm{K}^{+}$AlaPhe. 


\section{Complete Reference 33.}

M. J. Frisch, G. W. Trucks, H. B. Schlegel, G. E. Scuseria, M. A. Robb, J. R. Cheeseman, J. A. Montgomery, Jr., T. Vreven, K. N. Kudin, J. C. Burant, J. M. Millam, S. S. Iyengar, J. Tomasi, V. Barone, B. Mennucci, M. Cossi, G. Scalmani, N. Rega, G. A. Petersson, H. Nakatsuji, M. Hada, M. Ehara, K. Toyota, R. Fukuda, J. Hasegawa, M. Ishida, T.

Nakajima, Y. Honda, O. Kitao, H. Nakai, M. Klene, X. Li, J. E. Knox, H. P. Hratchian, J. B. Cross, C. Adamo, J. Jaramillo, R. Gomperts, R. E. Stratmann, O. Yazyev, A. J. Austin, R. Cammi, C. Pomelli, J. W. Ochterski, P. Y. Ayala, K. Morokuma, G. A. Voth, P. Salvador, J. J. Dannenberg, V. G. Zakrzewski, S. Dapprich, A. D. Daniels, M. C. Strain, O. Farkas, D. K. Malick, A. D. Rabuck, K. Raghavachari, J. B. Foresman, J. V. Ortiz, Q. Cui, A. G. Baboul, S. Clifford, J. Cioslowski, B. B. Stefanov, G. Liu, A. Liashenko, P. Piskorz, I. Komaromi, R. L. Martin, D. J. Fox, T. Keith, M. A. Al-Laham, C. Y. Peng, A. Nanayakkara, M. Challacombe, P. M. W. Gill, B. Johnson, W. Chen, M. W. Wong, C. Gonzalez, and J. A. Pople, Gaussian 03, Gaussian, Inc., Pittsburgh PA, 2003.

\section{End of Supplementary Material}




\section{Keywords:}

Ion spectroscopy; IR spectroscopy; mass spectrometry; peptides; alkali complexes

\section{Graphic and text for Table of Contents:}

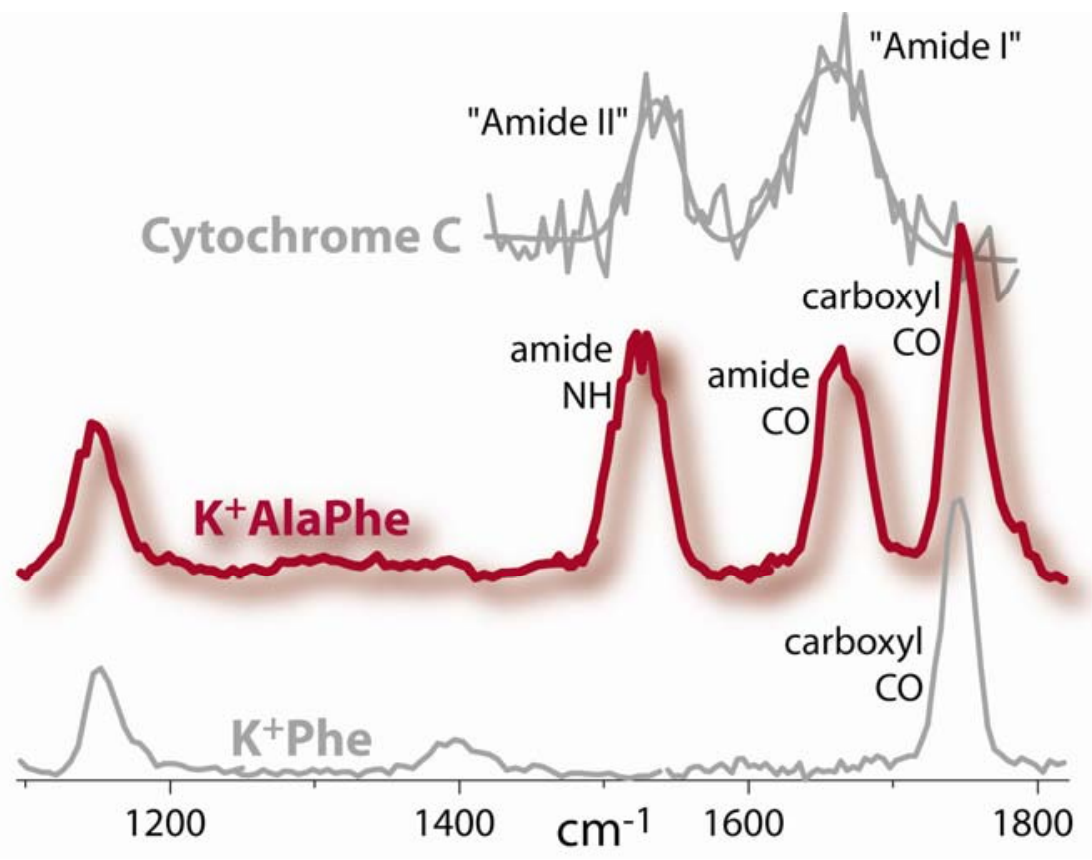

Dipeptide Ion Complexes: Gas-phase IR spectra of $\mathrm{Na}^{+}$and $\mathrm{K}^{+}$dipeptide complexes are newly accessible using a free-electron laser light source. The spectra display vibrational features characteristic of both mono-amino acid complexes and also proteins, showing, as in the figure, how the dipeptides offer a spectroscopic bridge from small to large peptide systems. 